\title{
Silica coating influences the corona and biokinetics of cerium oxide nanoparticles
}

\author{
Nagarjun V. Konduru', Renato J. Jimenez ${ }^{1}$, Archana Swami ${ }^{1}$, Sherri Friend ${ }^{2}$, Vincent Castranova ${ }^{3}$, \\ Philip Demokritou ${ }^{1}$, Joseph D. Brain ${ }^{1}$ and Ramon M. Molina ${ }^{1 *}$
}

\begin{abstract}
Background: The physicochemical properties of nanoparticles (NPs) influence their biological outcomes.

Methods: We assessed the effects of an amorphous silica coating on the pharmacokinetics and pulmonary effects of $\mathrm{CeO}_{2} \mathrm{NPs}$ following intratracheal (IT) instillation, gavage and intravenous injection in rats. Uncoated and silica-coated $\mathrm{CeO}_{2} \mathrm{NPs}$ were generated by flame spray pyrolysis and later neutron-activated. These radioactive NPs were IT-instilled, gavaged, or intravenously (IV) injected in rats. Animals were analyzed over 28 days post-IT, 7 days post-gavage and 2 days post-injection.

Results: Our data indicate that silica coating caused more but transient lung inflammation compared to uncoated $\mathrm{CeO}_{2}$. The transient inflammation of silica-coated $\mathrm{CeO}_{2}$ was accompanied by its enhanced clearance. Then, from 7 to 28 days, clearance was similar although significantly more ${ }^{141} \mathrm{Ce}$ from silica-coated (35\%) was cleared than from uncoated $(19 \%)^{141} \mathrm{CeO}_{2}$ in 28 days. The protein coronas of the two NPs were significantly different when they were incubated with alveolar lining fluid. Despite more rapid clearance from the lungs, the extrapulmonary ${ }^{141} \mathrm{Ce}$ from silica-coated ${ }^{141} \mathrm{CeO}_{2}$ was still minimal $(<1 \%)$ although lower than from uncoated ${ }^{141} \mathrm{CeO}_{2} \mathrm{NPs}$. Post-gavage, nearly $100 \%$ of both NPs were excreted in the feces consistent with very low gut absorption. Both IV-injected ${ }^{141} \mathrm{CeO}_{2}$ NP types were primarily retained in the liver and spleen. The silica coating significantly altered the plasma protein corona composition and enhanced retention of ${ }^{141} \mathrm{Ce}$ in other organs except the liver.
\end{abstract}

Conclusion: We conclude that silica coating of nanoceria alters the biodistribution of cerium likely due to modifications in protein corona formation after IT and IV administration.

Keywords: Nanoceria, Bioavailability, Protein corona, Silica

\section{Background}

With rapid growth in nanotechnology-enabled consumer products, engineered nanomaterials (ENMs) are increasingly common. At the same time, there are rising public concerns about adverse effects of ENMs on human health and the environment. Among the ENMs introduced into the global nanotechnology market, nanoceria $\left(\mathrm{CeO}_{2}\right)$ has moved to the fore with a wide array of applications. The ability of cerium to switch oxidation states between $\mathrm{Ce}$ (III) and Ce (IV) is crucial for many nanobiomedical applications [1-4]. Further, parameters such as the method employed to synthesize $\mathrm{CeO}_{2}$, its particle size, and the

\footnotetext{
* Correspondence: rmolina@hsph.harvard.edu

${ }^{1}$ Molecular and Integrative Physiological Sciences Program, Department of Environmental Health, Harvard T.H. Chan School of Public Health, 665

Huntington Avenue, Boston, MA 02115, USA

Full list of author information is available at the end of the article
}

extent of doping with other agents may alter the cerium oxidation state $[3,5]$.

The toxicity data on $\mathrm{CeO}_{2}$ from studies undertaken during the last decade are mixed and report a range of biological effects [6]. A number of in vivo and in vitro studies evaluating the biological effects of $\mathrm{CeO}_{2}$ have reported toxicity and oxidative stress [7-10]. However, recently there are also reports highlighting putative antioxidant activity of $\mathrm{CeO}_{2}$ and its ability to protect against oxidative stress-driven disorders [11-13]. Baer et al. have shed light on the influence of synthesis method, particle size and aging of $\mathrm{CeO}_{2}$ on biological outcomes [5]. Many studies have underscored the need for defining nanoparticle characteristics employed in biological studies. There are conflicting data on $\mathrm{CeO}_{2}$ toxicity and the consequences of different concentrations $[14,15]$. 
It is important to consider the extent of particle agglomeration in air and liquid media as a crucial factor contributing to discrepancies between in vivo inhalation versus instillation studies. Nanoparticle agglomeration is primarily influenced by NP intrinsic properties such as surface chemistry, charge, and primary particle size, but also from properties of suspending medium such as ionic strength [16-19].

Nanoparticle recognition by alveolar macrophages is a determinant of effective lung clearance. There is evidence that particle agglomeration aids in promotion of effective phagocytosis in alveolar macrophages; smaller $(<100 \mathrm{~nm})$ and more abundant structures may make macrophage mediated "surveillance" less effective [20]. Scientists are creating nanoparticles with functional surfaces designed to reduce inflammogenicity and lower toxicity while improving useful physicochemical properties. Developing strategies to mitigate toxicity of NPs without altering their core properties (a safer-by-design approach) is a vigorously pursued area of research [21-23]. In some cases, surface encapsulation of nanomaterials with a thin layer of amorphous silica renders them less cytotoxic and reduces DNA damage. Coating nanoparticles with amorphous silica can enhance nanoparticle stability in colloidal suspensions and facilitate effective uptake by professional phagocytes, stem cells, and other cell types with reduced toxicity [24-26]. Unlike crystalline silica that induces sustained inflammation and resultant fibrosis, amorphous silica evokes a transient and reversible inflammatory response [27].

We recently investigated the pulmonary clearance and extrapulmonary translocation of radiolabled $\mathrm{Ce}$ after intratracheal instillation of $\mathrm{CeO}_{2}$ [15]. Our study showed that only $12 \%$ of the instilled Ce dose was cleared from the rat lung during 28 days post-exposure. In another investigation, we found that inhalation of $\mathrm{CeO}_{2}$ caused more lung injury and inflammation than $\mathrm{CeO}_{2}$ coated with amorphous silica after one day post-exposure [28]. Previous reports have proposed that the protein corona formed on particles can influence biological effects [29]. To our knowledge this is the first study investigating the influence of surface properties of cerium oxide nanoparticles on protein corona formation, pulmonary effects, and the translocation and distribution of nanoceria after pulmonary and intravenous administration. We employed amorphous silica coating as a model to test the hypothesis that surface coating of $\mathrm{CeO}_{2}$ would alter its protein corona and thus influence the biokinetics of the core nanoceria. We chose nanoceria due to its slow lung clearance and relatively low solubility [15, 30-32]. The aim of our study was to compare the clearance kinetics and bioavailability of cerium after intratracheal, intragastric, and intravenous administration of silica-coated versus uncoated $\mathrm{CeO}_{2}$ in rats.

\section{Results}

Synthesis and characterization of $\mathrm{CeO}_{2}$ and silica-coated $\mathrm{CeO}_{2}$

Uncoated and silica-coated $\mathrm{CeO}_{2}$ were made by flame spray pyrolysis using the Versatile Engineered Nanomaterial Generation System (VENGES) at Harvard University [33]. Detailed physicochemical and morphological characterization of these NPs was reported earlier [21, 28]. In summary, the uncoated and silica-coated $\mathrm{CeO}_{2}$ had a cubic fluorite-like structure (Fig. 1). A nanothin (2-4 nm) amorphous silica layer hermetically encapsulated the $\mathrm{CeO}_{2}$ core in a coating reactor after their initial synthesis in an aerosol reactor [21] (Fig. 1b). The silica coating on the surface was revealed as fine optically transparent film surrounding the dark and opaque $\mathrm{CeO}_{2}$, as verified by $\mathrm{X}$ ray diffraction (XRD) and electron microscopy analyses. The average crystal size of the primary uncoated and silica-coated NPs was 32.9 and $32.6 \mathrm{~nm}$, respectively. Their specific surface areas (SSA) were $28 \mathrm{~m}^{2} / \mathrm{g}$ (uncoated) and $27.8 \mathrm{~m}^{2} / \mathrm{g}$ (silica-coated) (Table 1). The extent of the silica coating was assessed by X-ray photoelectron spectroscopy and by photocatalytic methods. The persistence of the silica coating in the lungs of rats was at least 3 days after inhalation [34].

Assessments by dynamic light scattering (DLS) showed that as an aqueous dispersion the particles essentially behaved as "nanoagglomerates" of $136 \pm 1.1 \mathrm{~nm}$ (uncoated) and $208 \pm 2.9 \mathrm{~nm}$ (silica-coated). The hydrodynamic diameters of the two $\mathrm{CeO}_{2}$ types are shown in Table 1. The zeta potential of NP suspensions was also evaluated in distilled water. Uncoated $\mathrm{CeO}_{2}$ exhibited a positive zeta potential $(34.5 \pm 3.1 \mathrm{mV})$ and the silica coating changed the zeta potential to negative $-26.8 \pm 0.3 \mathrm{mV}$ (Table 1). DLS analysis was also performed on both nanoceria after in vitro incubation with harvested rat bronchoalveolar lining (BAL) fluid to determine if the lipoprotein corona alters agglomeration size and zeta potential. We found that this corona significantly increased the hydrodynamic diameter (136 to $1463 \mathrm{~nm}$ ) and changed the zeta potential (34.5 to $-20.8 \mathrm{mV}$ ) of uncoated $\mathrm{CeO}_{2}$. The effects of the lipoprotein corona on silica-coated $\mathrm{CeO}_{2}$ were more modest (Table 1). After incubation in rat plasma and the formation of the protein corona, the hydrodynamic diameters of both $\mathrm{CeO}_{2}$ NP types were significantly increased and the surface charge of uncoated $\mathrm{CeO}_{2}$ was also altered from positive to negative zeta potential (Table 1). Similar to protein corona formed with BAL incubation, the increase in $\mathrm{D}_{\mathrm{H}}$ with plasma protein corona formation was more pronounced with uncoated $\mathrm{CeO}_{2} \mathrm{NPs}$.

\section{Pulmonary responses to intratracheally instilled $\mathrm{CeO}_{2}$ and silica-coated $\mathrm{CeO}_{2}$}

We compared the pulmonary responses of rats to uncoated versus silica-coated $\mathrm{CeO}_{2}$ at 1 and 5 days after 


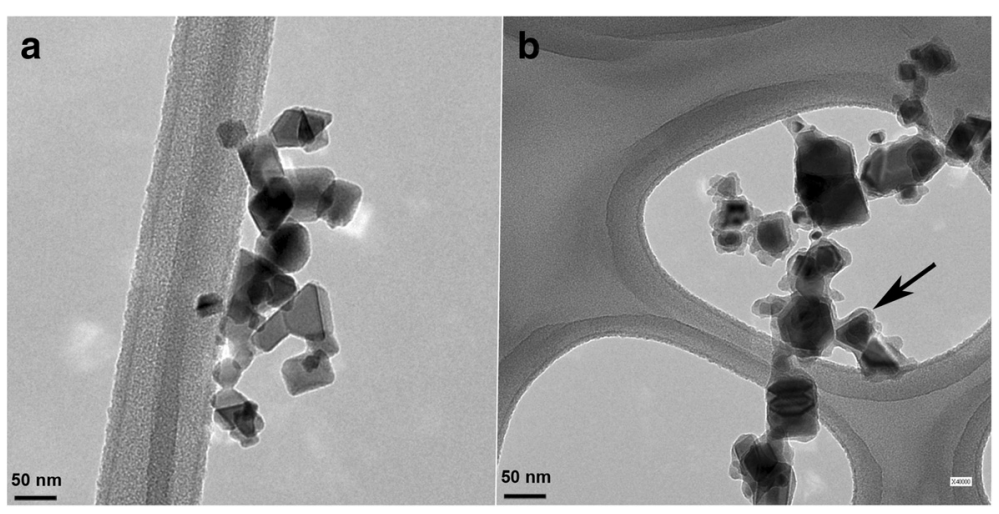

Fig. 1 Appearance of $\mathrm{CeO}_{2} \mathrm{NPs}$ used in this study. a Electron micrograph of uncoated and $\mathbf{b}$ silica-coated $\mathrm{CeO}_{2} \mathrm{NPS}$. Arrow shows a thin silica coating

IT instillation in rats as described previously [35]. This experiment was performed to also determine the safe dose for intratracheal instillation of $\mathrm{CeO}_{2}$ and silicacoated $\mathrm{CeO}_{2}$ NPs where inflammation or injury was minimal. Groups of 6 rats ( $272 \pm 13$ g body weight) were instilled with $0.2,1$ or $5 \mathrm{mg} / \mathrm{kg}$ of each type of $\mathrm{CeO}_{2}$. Control animals were instilled with an equivalent volume of distilled water. We found that coated and uncoated $\mathrm{CeO}_{2}$ NPs induced a dose-dependent injury and inflammation as indicated by increased neutrophils (Fig. 2a) in the BAL fluid at $24 \mathrm{~h}$ post-instillation. Both NPs also increased the levels of myeloperoxidase (MPO), albumin and lactate dehydrogenase (LDH) (Fig. 2b). Interestingly, the numbers of lavaged macrophages increased for uncoated and decreased for silica-coated $\mathrm{CeO}_{2}$ with increasing dose (Fig. 2c). At 0.2 and $1 \mathrm{mg} / \mathrm{kg}$ doses, only the silica-coated $\mathrm{CeO}_{2}$ instilled rats showed elevated LDH, MPO, and albumin levels. However, five days post-dosing with $1 \mathrm{mg} /$ $\mathrm{kg}$ of silica-coated $\mathrm{CeO}_{2}$ there were decreased PMN counts (Fig. 2d). At this time, there were also reductions in other inflammatory biomarkers such as MPO, albumin and LDH (Fig. 2e). However, significant increase in macrophage numbers was observed in silicacoated $\mathrm{CeO}_{2}$ groups (Fig. 2f).
In vivo clearance and translocation of ${ }^{141} \mathrm{CeO}_{2}$ and silica-coated ${ }^{141} \mathrm{CeO}_{2}$ after IT instillation in rats

The lung levels of ${ }^{141} \mathrm{Ce}$ after a single IT instillation of either radioactive uncoated $\mathrm{CeO}_{2}$ or silica-coated $\mathrm{CeO}_{2}$ were evaluated in rats for 28 days. Animals were sacrificed at $5 \mathrm{~min}$, and 2, 7 and 28 days post-instillation and various organs were collected to determine the retained cerium concentration. The lung clearance profiles for both nanoparticle types showed no differences during the first two days post-IT instillation. Interestingly, the lung clearance was markedly different between day 2 and day 7 for the two NPs (Fig. 3a). We observed that $\sim 22 \%$ of the ${ }^{141} \mathrm{Ce}$ from the silica-coated $\mathrm{CeO}_{2}$ and only $\sim 8 \%$ of the ${ }^{141} \mathrm{Ce}$ from the uncoated $\mathrm{CeO}_{2}$ dose disappeared from the lungs during this period. Between day 7 and day 28 post-IT instillation, the difference in the fraction of cleared NPs was statistically significant but relatively small $(8.1 \%$ for uncoated ${ }^{141} \mathrm{CeO}_{2}$ vs. $10.4 \%$ for silica-coated $\mathrm{CeO}_{2}$ ). By 28 days postinstillation, $\sim 81 \%$ of uncoated $\mathrm{CeO}_{2}$ still remained in the lungs. Coating of $\mathrm{CeO}_{2}$ with amorphous silica enhanced the overall clearance of $\mathrm{CeO}_{2}$ by an additional $16 \%$.

Translocation of radioactive cerium from the lungs to other organs was evaluated by measuring ${ }^{141} \mathrm{Ce}$ in the different collected tissues. Low detectable fractions of radioactivity for Ce from both NP types were found in the liver,

Table 1 Physicochemical characterization of nanoparticles used

\begin{tabular}{|c|c|c|c|c|c|c|}
\hline & $\mathrm{CeO}_{2}$ in $\mathrm{DI}$ water & Silica-coated $\mathrm{CeO}_{2}$ in DI water & $\mathrm{CeO}_{2}$ in $\mathrm{BAL}$ & Silica-coated $\mathrm{CeO}_{2}$ in BAL & $\mathrm{CeO}_{2}$ in plasma & $\begin{array}{l}\text { Silica-coated } \mathrm{CeO}_{2} \\
\text { in plasma }\end{array}$ \\
\hline $\mathrm{SSA}\left(\mathrm{m}^{2} / \mathrm{g}\right)$ & 28.0 & 27.8 & N.A. & N.A. & N.A. & N.A. \\
\hline $\mathrm{D}_{\text {xrd }}(\mathrm{nm})$ & 32.9 & 32.6 & N.A. & N.A. & N.A. & N.A. \\
\hline $\mathrm{D}_{\mathrm{H}}(\mathrm{nm})$ & $136 \pm 1$ & $208 \pm 3$ & $1463 \pm 88$ & $460 \pm 12$ & $2572 \pm 372$ & $242 \pm 3$ \\
\hline$\zeta(\mathrm{mv})$ & $34.5 \pm 3.1$ & $-26.8 \pm 0.3$ & $-20.8 \pm 3.4$ & $-15.4 \pm 2.0$ & $-25.2 \pm 2.8$ & $-31.8 \pm 2.7$ \\
\hline
\end{tabular}

SSA - specific surface area

$D_{x r d}$ - primary particle size based on X-ray diffraction

$D_{H}$ - hydrodynamic diameter

$\zeta$ - zeta potential

N.A. - not applicable 

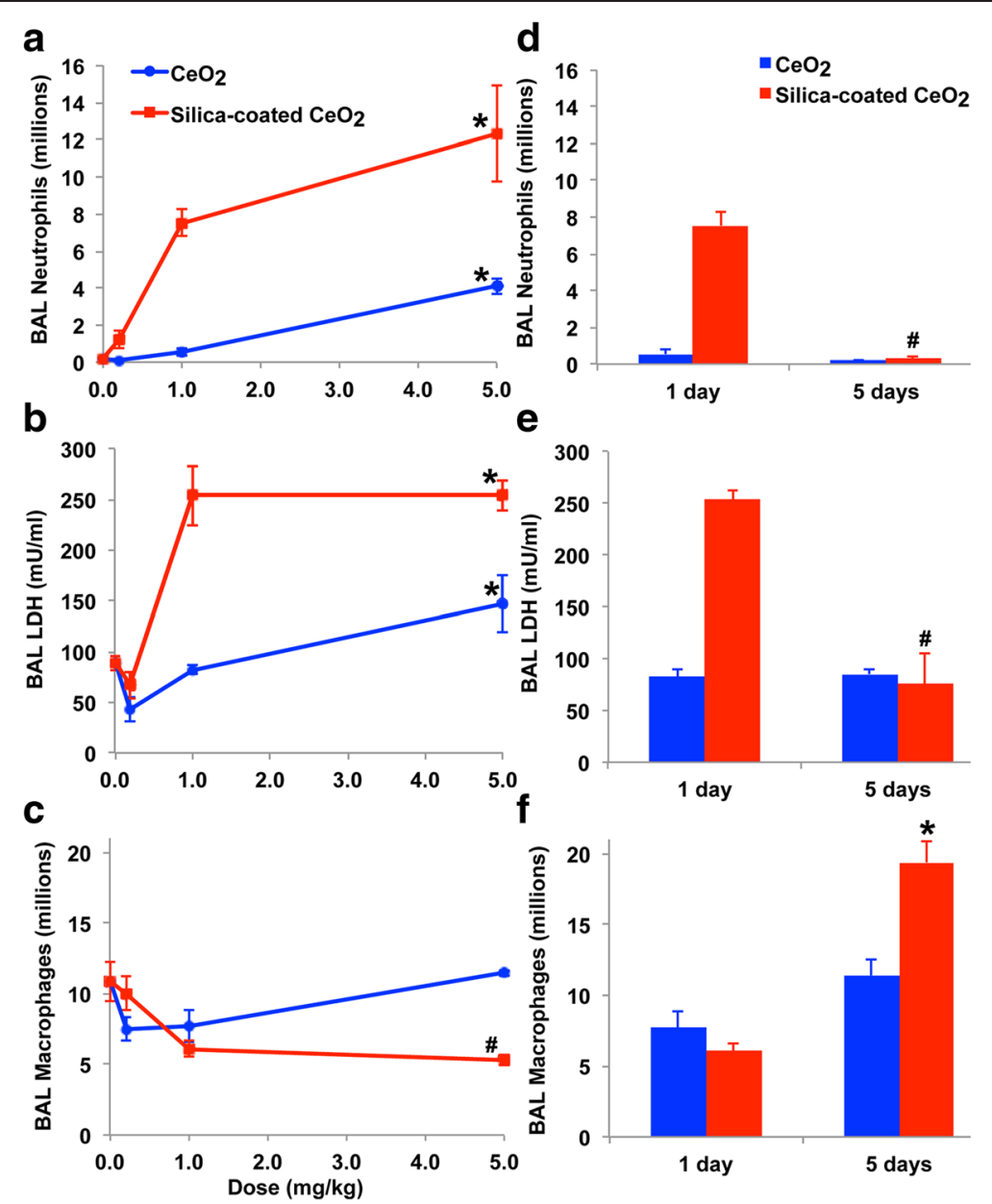

Fig. 2 Bronchoalveolar lavage analysis after IT instillation of uncoated or silica-coated $\mathrm{CeO}_{2} \mathrm{NPs}$. a Dose-dependent increases in lavaged neutrophils and b lactate dehydrogenase levels in BAL at $24 \mathrm{~h}$ post-instillation. $\mathbf{c}$ Lavaged macrophages increased with uncoated but decreased with silica-Coated $\mathrm{CeO}_{2}$ at the highest NP dose. $\mathbf{d}$ Lavaged neutrophils and e lactate dehydrogenase, MPO and albumin (data not shown) returned to normal levels but f macrophage recruitment was observed at 5 days post-instillation of $1 \mathrm{mg} / \mathrm{kg} \mathrm{CeO}_{2} .{ }^{*}{ }^{*}$ increased, \# decreased, $P<0.05$, MANOVA. Data are mean \pm SEM, $n=5 /$ group)

bone/bone marrow, spleen and kidneys $(<1 \%)$ (Fig. 3b). Estimated tissue cerium concentration in these organs were higher for uncoated $\mathrm{CeO}_{2}$ (Table 2). The elimination of ${ }^{141} \mathrm{Ce}$ from both particle types was mostly via the feces (Fig. 4b) and to a much lesser extent via the urine (Fig. 4a). Furthermore, we found that the total recovered ${ }^{141} \mathrm{Ce}$ in examined tissues, feces, and urine was significantly higher in uncoated than silica-coated $\mathrm{CeO}_{2}$ (Figs. 3 and 4). In the case of silica-coated $\mathrm{CeO}_{2}$, we speculate that the missing radioactivity may have been in organs not examined such as lymph nodes, adipose tissue, pancreas, adrenals, teeth, nails, tendons, nasal tissues, and the rest of the head.

\section{Biodistribution of $\mathrm{CeO}_{2}$ within the lungs and protein corona formation}

Since the protein corona on NP surfaces may modulate their cell interaction and overall biological effects, we examined the composition of adsorbed proteins on the NP surface when incubated with collected cell-free BAL fluid. First, we found that incubation of NPs in concentrated BAL fluid significantly altered their aggregate sizes (Table 1 ). Compared with the suspension in deionized water, both nanoceria types exhibited larger and more variable hydrodynamic diameter. Uncoated nanoceria also formed larger agglomerates than the coated NPs. In addition, we found that the total amount of adsorbed protein was significantly higher in silica-coated than uncoated $\mathrm{CeO}_{2}$ especially albumin, C3, and transferrin (Fig. 5a, b). However, we found no differences in the quantitative distribution of the two NP types $24 \mathrm{~h}$ post-IT instillation among the three measured compartments (Fig. 5c). The majority of ${ }^{141} \mathrm{Ce}$ activity was associated with the lavaged lungs. Additionally, hyperspectral imaging analysis, to determine the extent of NP uptake in BAL cells after 5 days post-IT instillation, revealed a higher number of particle-containing cells in the silica-coated than uncoated group (Fig. 6). 


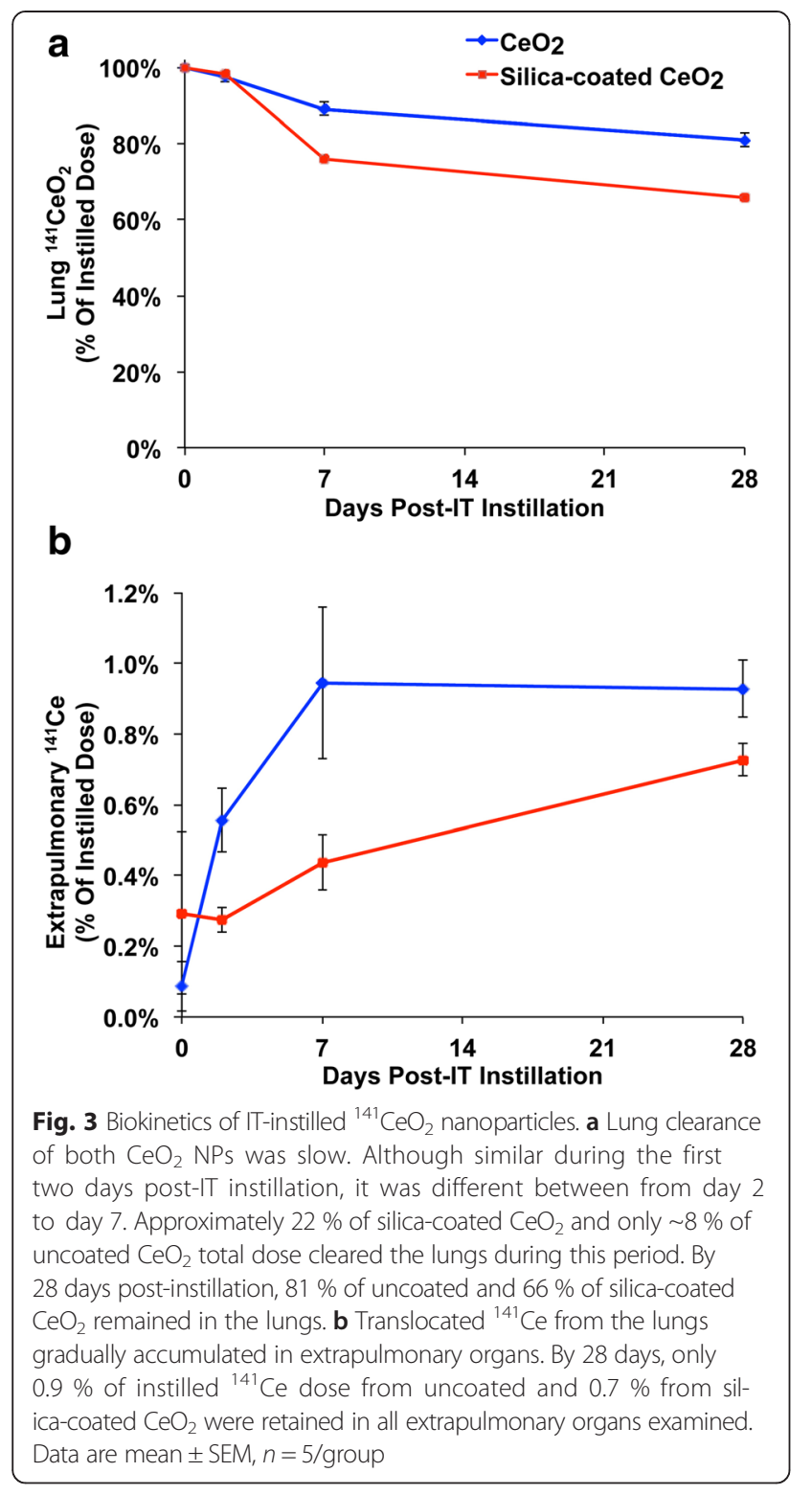

\section{Biodistribution of uncoated and silica-coated $\mathrm{CeO}_{2}$ after} gavage administration in rats

At $5 \mathrm{~min}$ and 7 days post-gavage of uncoated $\mathrm{CeO}_{2}$ or silica-coated $\mathrm{CeO}_{2}$ we measured absorption of ${ }^{141} \mathrm{Ce}$ from the gut. As expected, nearly $100 \%$ of the dose was recovered at $5 \mathrm{~min}$ in the stomach for both types of NPs (Fig. 7a). The ${ }^{141}$ Ce levels in tissues other than the gastrointestinal (GI) tract were extremely low (0.004\% for uncoated, $0.002 \%$ for silica-coated $\mathrm{CeO}_{2}$ ) by day 7 (Fig. 7b). Very low levels of ${ }^{141} \mathrm{Ce}$ were excreted in the urine (Fig. 7c) and nearly $99 \%$ of both $\mathrm{CeO}_{2}$ NPs was excreted in feces by day 7 (Fig. 7d). As there was very low radioactivity detected in any of the collected organs and in urine samples over a period of 7 days, we conclude that both uncoated and silica-coated $\mathrm{CeO}_{2}$ do not significantly translocate through the intestinal barrier.
Table 2 Cerium concentration at 28 days post-instillation of uncoated or silica-coated $\mathrm{CeO}_{2} \mathrm{NPS}$

\begin{tabular}{|c|c|c|}
\hline & $\mathrm{CeO}_{2}$ & Silica-coated $\mathrm{CeO}_{2}$ \\
\hline & $\mathrm{ng} / \mathrm{g} \pm \mathrm{SE}$ & $\mathrm{ng} / \mathrm{g} \pm \mathrm{SE}$ \\
\hline Lungs & $136836.67 \pm 4084.19$ & $95193.25 \pm 1766.39 *$ \\
\hline Liver & $59.35 \pm 10.19$ & $33.10 \pm 2.78 *$ \\
\hline Bone & $38.13 \pm 5.14$ & $21.97 \pm 2.87 *$ \\
\hline Cecum & $33.62 \pm 10.95$ & $24.15 \pm 6.58$ \\
\hline Large intestine & $28.11 \pm 8.94$ & $24.33 \pm 8.01$ \\
\hline Bone marrow & $16.55 \pm 2.55$ & $9.44 \pm 1.05 *$ \\
\hline Spleen & $13.90 \pm 6.21$ & $3.83 \pm 0.59$ \\
\hline Stomach & $12.77 \pm 2.09$ & $16.82 \pm 8.64$ \\
\hline Kidneys & $10.40 \pm 1.13$ & $5.52 \pm 0.35 *$ \\
\hline Small intestine & $10.14 \pm 1.49$ & $7.94 \pm 2.20$ \\
\hline Heart & $1.95 \pm 0.54$ & $0.21 \pm 0.08 *$ \\
\hline Testes & $0.54 \pm 0.08$ & $0.13 \pm 0.04 *$ \\
\hline Skeletal muscle & $0.46 \pm 0.21$ & $0.20 \pm 0.09$ \\
\hline Brain & $0.43 \pm 0.24$ & $0.15 \pm 0.11$ \\
\hline Skin & $0.38 \pm 0.08$ & $0.16 \pm 0.01 *$ \\
\hline Plasma & $0.14 \pm 0.09$ & $0.04 \pm 0.04$ \\
\hline RBC & $0.04 \pm 0.04$ & $0.08 \pm 0.06$ \\
\hline
\end{tabular}

Data are mean $\pm \mathrm{SE} n g / g$ cerium concentration, $n=5 /$ group Ce concentration was estimated ( $\left.\mathrm{ng} / \mu \mathrm{Ci}_{\mathrm{NPs}} \times \mu \mathrm{Ci} / \mathrm{g}_{\text {tissue }}\right)$ ${ }^{*} P<0.05, \mathrm{CeO}_{2}$ vs. silica-coated $\mathrm{CeO}_{2}$

Tissue concentration of cerium at 7 days post-gavage is shown in Table 3.

Tissue distribution of ${ }^{141} \mathrm{CeO}_{2}$ and silica-coated ${ }^{141} \mathrm{CeO}_{2}$ NPs after intravenous injection

The distribution of intravenously injected NPs at $2 \mathrm{~h}$ and 2 days post-injection is shown in Fig. 8a and b, respectively. Radioactive ${ }^{141} \mathrm{Ce}$ from both NP types was predominantly retained in the liver, spleen, and bone, organs that typically take up circulating particles by macrophages with access to the blood. The silica coating led to a redistribution of ${ }^{141} \mathrm{Ce}$ over a period of 2 days from the liver to the spleen and other organs (Fig. 8b). The silica coating also enhanced the tissue concentration of ${ }^{141} \mathrm{Ce}$ in several organs but decreased in the liver (Tables 4 and 5).

To determine the influence of silica coating on NP-plasma protein interactions, we analyzed the hydrodynamic diameters of NPs and characterized the protein corona formed after incubation of NPs in rat plasma in vitro. We found significant increases in agglomerate sizes of both NP types compared to when suspended in protein-free deionized water (Table 1). We also found differences in the protein corona composition between the 2 NP types (Fig. 9a, b). The fecal excretion of ${ }^{141} \mathrm{Ce}$ post-injection of NPs during the first $24 \mathrm{~h}$ was far 


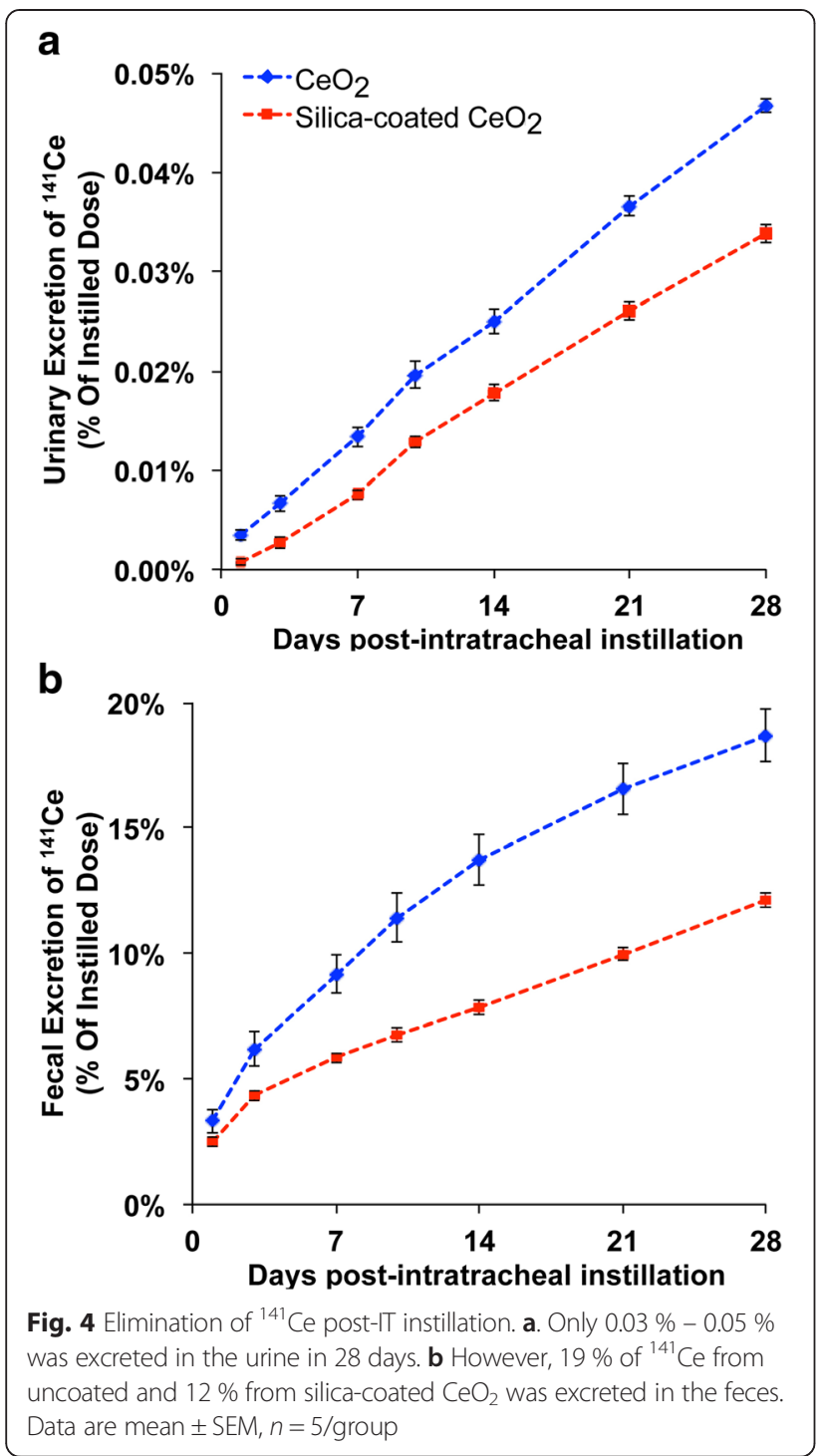

lower than after IT instillation (0.05\% v. $3 \%)$, suggesting that some $\mathrm{CeO}_{2}$ NPs in the lungs may be removed by mucociliary transport. It also suggests that absorbed cerium is eliminated slowly from the body.

\section{Discussion}

Progress in nanotechnology has produced a variety of nanoparticle generation systems which synthesize nanoparticles of desired size and properties. The in-house VENGES system employed in this study enabled us to control primary particle size and aerosol size distribution. This platform also allowed for in-flight coating of $\mathrm{CeO}_{2}$ with a nanothin layer of amorphous silica [21]. This flame-based silica-coating process has recently been explored as a means of high yield scalable manufacturing of silica-coated nanosized ENMs with cores of $\mathrm{TiO}_{2}$, $\mathrm{Fe}_{2} \mathrm{O}_{3}$, or Ag [36].
In this study, we sought to examine the effect of surface modification of $\mathrm{CeO}_{2}$ with amorphous silica on acute pulmonary responses as well as on $\mathrm{CeO}_{2}$ pharmacokinetics after IT instillation, gavage, and IV injection. We observed that exposure of rats to silica-coated $\mathrm{CeO}_{2}$ caused higher dose-dependent inflammatory responses compared to uncoated particles and a vehicle-only control group, as evidenced by increases in BAL parameters. However, the inflammatory effects induced by silicacoated $\mathrm{CeO}_{2}$ were transient and subsided by day 5 (Fig. 2d and e). This is consistent with our recent study in which $1 \mathrm{mg} / \mathrm{kg}$ dose of silica-coated $\mathrm{CeO}_{2} \mathrm{NPs}$ also caused higher but transient inflammation [34]. We note that these findings are in contrast to our previously published report on the toxic and inflammatory effects of the same particles after inhalation exposure, where we showed that inhaled silica-coated $\mathrm{CeO}_{2}$ induced less toxicity and inflammation after exposure for $2 \mathrm{~h}$ per day for 4 consecutive days [28]. This discordance may be explained based on the higher doses used here and the different exposure method (bolus IT instillation vs. inspired aerosols over $8 \mathrm{~h}$ ). Although IT instillation is a reliable method for administering a precise dose to the lungs, it differs from inhalation exposure in terms of particle distribution, dose rate, the extent of NP agglomeration and ressulting patterns of injury and clearance. Baisch et al. observed that inflammatory responses following intratracheal instillation were higher than those seen following whole body inhalation for single and repeated exposures of titanium dioxide NPs when deposited doses were comparable [37].

\section{Fate of intratracheally-instilled nanoceria}

The lung clearance of uncoated $\mathrm{CeO}_{2}$ observed in this study was similar to our recent report on $\mathrm{CeO}_{2} \mathrm{NM}-212$. NM-212 was synthesized by a precipitation method unlike the $\mathrm{CeO}_{2} \mathrm{NPs}$ used here which were flame-generated [38]. Our data are consistent with a study by $\mathrm{He}$ et al. where $63.9 \pm 8.2 \%$ of the intratracheally instilled dose still remained in the lungs after 28 days [31]. We found that the extent of silica-coated $\mathrm{CeO}_{2}$ clearance from the lung was significantly higher $(\sim 35 \%)$ than uncoated $\mathrm{CeO}_{2}$ $(\sim 19 \%)$. But an important finding was the significant influence of the silica coating on the lung clearance of $\mathrm{CeO}_{2}$ from days 2 to day 7 . This period of more rapid clearance coincided with the initial phase characterized by greater inflammation and increased air-blood barrier permeability.

As the pulmonary surfactant lies at the outermost aspect of the air-blood barrier, inhaled and deposited NPs first encounter the biomolecules of the alveolar lining layer. This fluid consists of an ultra-thin layer of aqueous hypophase and a surface active lipoprotein mixture usually known as the pulmonary surfactant layer [39]. Pulmonary surfactant is composed of $85-90 \% \mathrm{w} / \mathrm{w}$ phospholipids and 


\section{a}

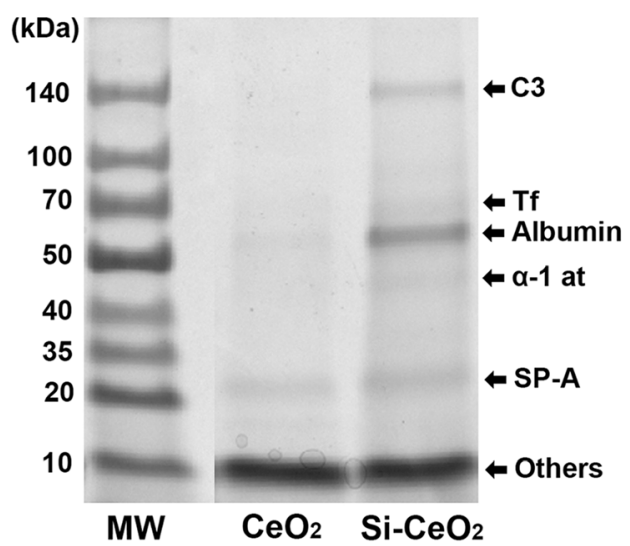

b

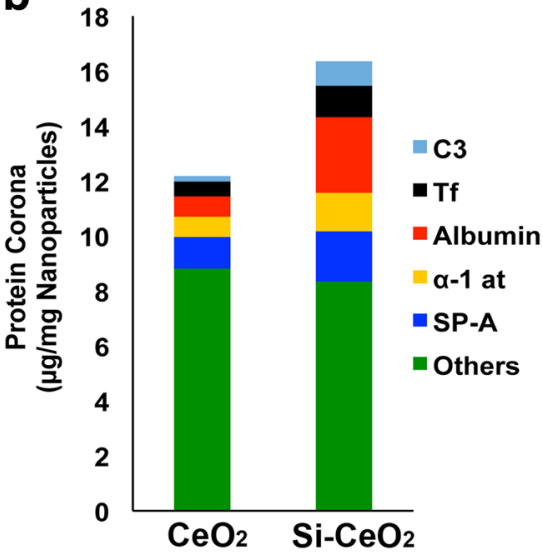

C

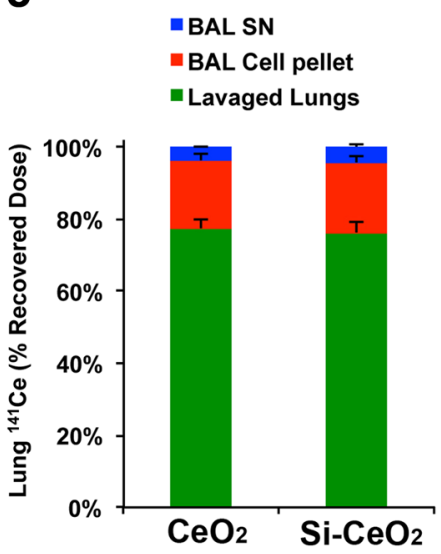

Fig. 5 Analysis of nanoparticles after incubation with BAL fluid. a NP-bound rat BAL proteins were analyzed by 1D gel electrophoresis and Mass Spectrometry. The molecular weights $(\mathrm{kDa})$ of reference proteins are shown in lane MW. Five proteins identified by LC-MS are indicated on right. b LC-MS profiles of the same five proteins show the influence of silica coating on the protein corona profile. c Compartmental distribution of neutron activated uncoated and silica-coated $\mathrm{CeO}_{2}$ at $24 \mathrm{~h}$ post-instillation. No significant differences in distribution were observed between the two $\mathrm{CeO}_{2} \mathrm{NPS}$. Data are mean $\pm \mathrm{SEM}, n=5 /$ group

$10 \% \mathrm{w} / \mathrm{w}$ proteins [40]. Adsorption of phospholipids and proteins on the NP surface takes place rapidly [41]. Therefore, it is reasonable to assume that interactions of NPs with lung cells occur mostly with the NP-lipoprotein complex and not with bare NP surfaces [42]. Importantly, the adsorption of proteins and phospholipids on NPs may modulate their overall biological effects $[43,44]$.

We examined the protein corona formed on the surface of our test NPs as they encounter the lung lining fluid. The incubation of NPs in BAL fluid significantly increased their hydrodynamic sizes and changed the zeta potential of $\mathrm{CeO}_{2}$ NPs likely due to their interactions with phospholipids and proteins. Presumably, instilled NPs would immediately acquire protein coronas in vivo changing their surface charge and extent of aggregation unlike those in water suspension and in dry aerosols. The type of proteins comprising the corona may also impact NP translocation [45]. Aggregate size alterations could also influence the pulmonary effects and translocation of the core nanoceria. Notably, we found significantly more protein adsorbed in the "hard corona" of silica-coated compared to uncoated $\mathrm{CeO}_{2}$. The amounts of specific proteins comprising the hard corona shown in Fig. 5b were based on NP mass ( $\mu \mathrm{g} / \mathrm{mg}$ NPs). When expressed as amount of protein per unit surface area $\left(\mu \mathrm{g} / \mathrm{m}^{2}\right)$ of NPs, silica-coated $\mathrm{CeO}_{2}$ still bind more BAL proteins than uncoated NPs. Significantly more albumin, SP-A, $\alpha-1$ antitrypsin, transferrin, and $\mathrm{C} 3$ proteins were present in the corona of silica-coated $\mathrm{CeO}_{2}$. These belong to the class of proteins that shuttle across the alveolar-epithelial barrier [46]. Receptor-mediated transport processes in the alveolar epithelium have been reported for albumin and transferrin [46]. Translocation of intratracheally instilled ${ }^{125}$ I-albumin from air spaces into the blood compartment has been reported previously [47]. Rapid translocation of synthetic organic NPs comprised of human serum albumin and a fluorophore has been demonstrated [48]. Whether this enhanced adsorption of albumin and transferrin onto silica- 


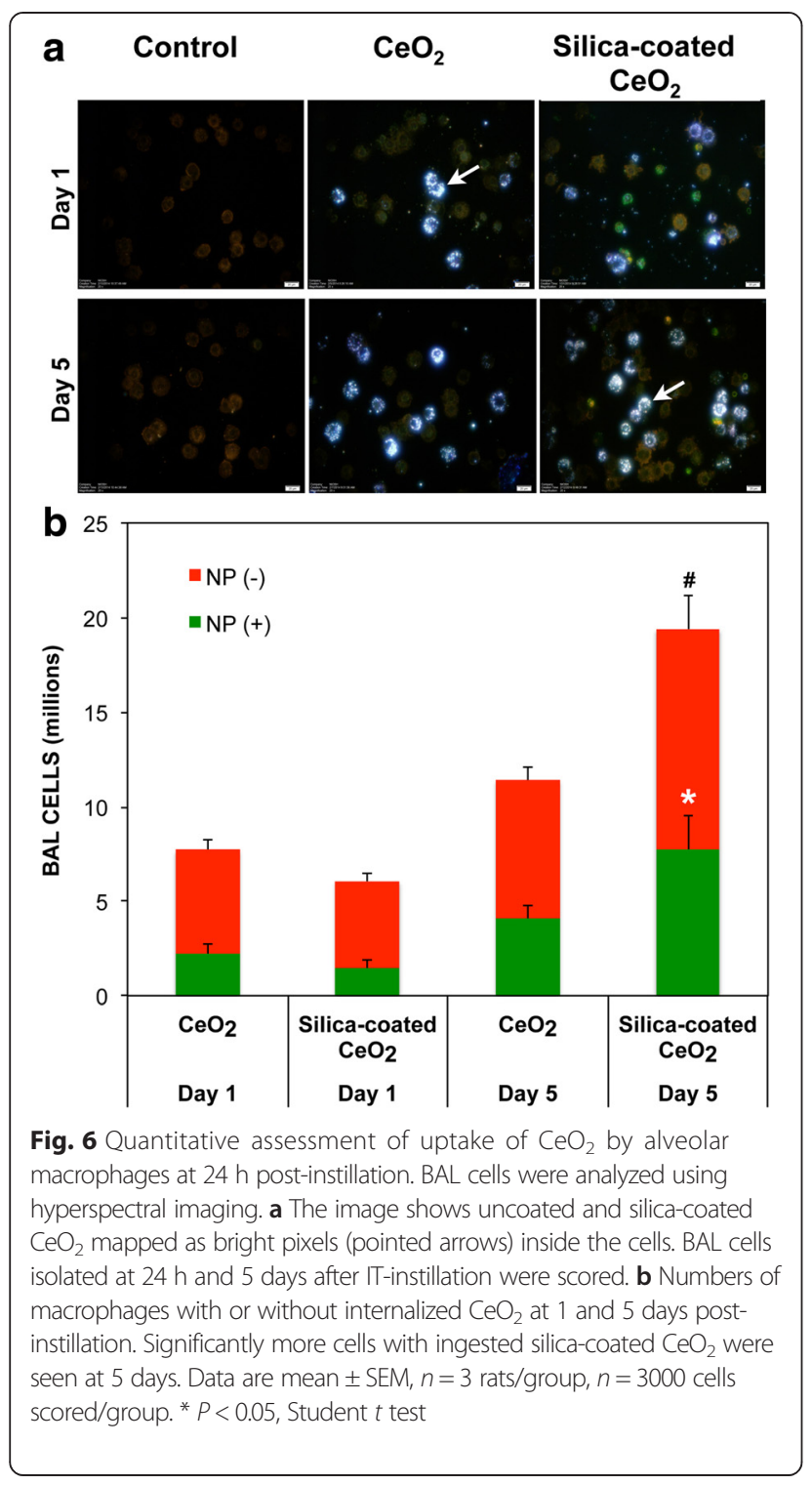

coated nanoceria contribute to their small but higher translocation through the lungs needs further investigation.

Studies have reported that some of the proteins present in BAL exhibit immunological functions (e.g., C3 and SP-A) [49-51]. It has been shown that coating of magnetite and $\mathrm{TiO}_{2}$ with SP-A improved their uptake in macrophages [52]. Our findings that the lipoprotein corona changes the agglomerate size and zeta potential of $\mathrm{CeO}_{2}$ also suggest that the corona can affect the manner in which alveolar macrophages interact, recognize, phagocytose, and process $\mathrm{CeO}_{2}$ NPs. Alveolar macrophages are the primary phagocytic cells for ultrafine particles in the lungs [53]. Particles may adhere to the surfaces of type I and type II epithelial cells as well, but lung parenchymal cells are less capable of phagocytosis [54]. AMs play a critical role in NP-induced inflammation and oxidative stress. Most of the deposited particles in the alveolar region are phagocytosed within a $24 \mathrm{~h}$ period after particle deposition, as long as the dose is not beyond the ingestion capacity of AMs [55, 56]. Notably, functionalized NPs are more effectively phagocytosed than non-functionalized NPs [57-60]. Recognition and phagocytosis of nanoparticles by AMs is a key component in nanoparticle dissolution and clearance.

We examined whether silica coating affects the distribution of $\mathrm{CeO}_{2}$ within the different lung compartments after the first $24 \mathrm{~h}$ post-instillation. We found no significant differences in the amount of radioactive $\mathrm{CeO}_{2}$ in lavaged alveolar cells, in cell-free supernatant, or in lavaged lungs. Furthermore, no significant difference was found in the number of AMs with internalized $\mathrm{CeO}_{2}$ NPs assessed by hyperspectral imaging of lavaged AMs. However, at 5 days post-instillation, significantly more AMs were found to have internalized silica-coated than uncoated $\mathrm{CeO}_{2}$. This enhanced uptake could be due to different corona profile, altered aggregate size or abundant recruitment of AMs observed with silica-coated $\mathrm{CeO}_{2}$. It is possible that this enhanced uptake of silica-coated $\mathrm{CeO}_{2}$ by activated AMs and the higher inflammation could lead to greater translocation of particles or particle-containing cells into the lymphatic system. For the lung parenchyma, clearance involves a slower phase, occurring in the alveoli. It consists of phagocytosis of particles from the lung surface by AMs and to a lesser extent by particles entering the lymphatics and subsequent accumulation in the regional lymph nodes.

We were unable to measure the lymphatic clearance of $\mathrm{CeO}_{2} \mathrm{NPs}$ since lymph nodes were not included in this study. However, we have previously shown that ${ }^{65} \mathrm{Zn}$ from ${ }^{65} \mathrm{ZnO}$ NPs was more significantly translocated to tracheobronchial lymph nodes when coated similarly with amorphous silica [22]. Interestingly, despite the greater clearance from the lungs, ${ }^{141} \mathrm{Ce}$ from silica-coated $\mathrm{CeO}_{2}$ was slightly lower in all the organs we examined $(0.73$ vs. $0.93 \%)$. The cerium concentration retained in the liver, bone, kidneys, heart, and testes was lower. Excretion in the feces was also lower (12 vs. $19 \%$ ).

\section{Fate of ingested nanoceria}

Data from animal and human studies show that inhaled nanoparticles are subject to different site-dependent clearance mechanisms [20]. These mechanisms include a fast clearance phase, which can be observed in the tracheobronchial region and is attributed to the mucociliary elimination with subsequent ingestion into the gastrointestinal tract and excretion via the feces. Thus, the oral exposure to nanoparticles is pertinent from an environmental exposure perspective, such as the ultrafine fraction of air pollution exposures. As a surrogate for entry of particles into the GI tract from the lungs, we also investigated the influence of silica coating on the bioavailability of 

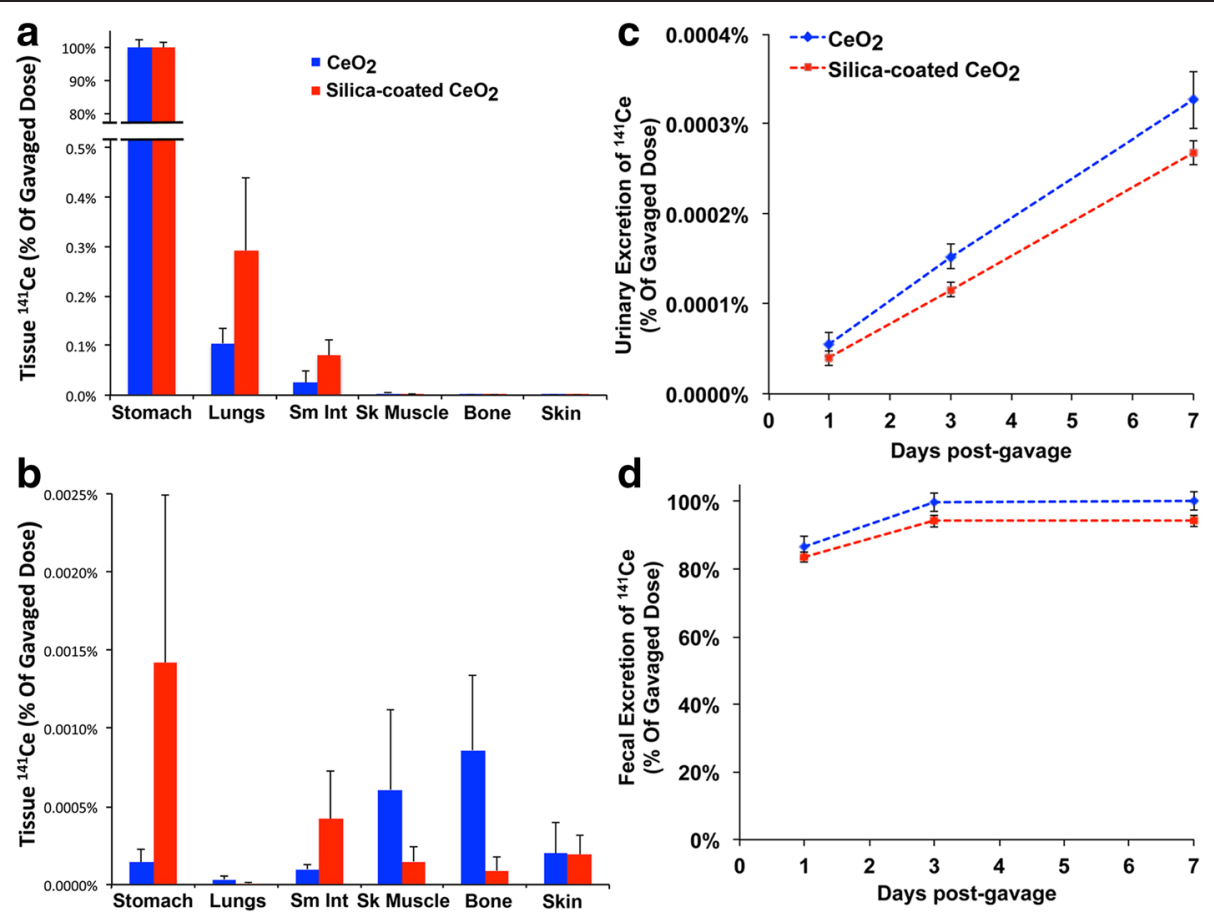

Fig. 7 Tissue distribution of ${ }^{141} \mathrm{Ce}$ post-gavage. a Immediately post-gavage, nearly $100 \%$ of both $\mathrm{CeO}_{2}$ were recovered in the stomach and to much lesser extent in other organs. b At 7 days post-gavage, the total tissue ${ }^{141}$ Ce detected in all organs examined was negligible $(0.003 \pm 0.001 \%)$. c By 7 days post-gavage, less than $0.0004 \%$ of dose was excreted in the urine. $\mathbf{d}$ Elimination of ${ }^{141} \mathrm{Ce}$ via the feces was nearly $100 \%$ from uncoated and $94 \%$ from silica-coated $\mathrm{CeO}_{2}$. Data are mean $\pm \mathrm{SEM}, n=5 /$ group

Table 3 Cerium concentration in different tissues at 7 days after gavage administration of uncoated or silica-coated $\mathrm{CeO}_{2} \mathrm{NPs}$

\begin{tabular}{lcc}
\hline & \multicolumn{1}{c}{$\mathrm{CeO}_{2}$} & Silica-coated $\mathrm{CeO}_{2}$ \\
\cline { 2 - 3 } & $\mathrm{ng} / \mathrm{g} \pm \mathrm{SE}$ & $0.07 \pm 0.03$ \\
\hline Lungs & $0.27 \pm 0.16$ & $0.07 \pm 0.03$ \\
Liver & $0.11 \pm 0.04$ & $0.06 \pm 0.06$ \\
Bone & $0.55 \pm 0.31$ & $0.18 \pm 0.13$ \\
Cecum & $0.22 \pm 0.08$ & $0.20 \pm 0.15$ \\
Large intestine & $0.76 \pm 0.72$ & $0.25 \pm 0.25$ \\
Bone marrow & $0.00 \pm 0.00$ & $0.15 \pm 0.15$ \\
Spleen & $0.06 \pm 0.06$ & $2.64 \pm 1.84$ \\
Stomach & $0.31 \pm 0.18$ & $0.09 \pm 0.04$ \\
Kidneys & $0.13 \pm 0.13$ & $0.39 \pm 0.27$ \\
Small intestine & $0.12 \pm 0.05$ & $0.35 \pm 0.21$ \\
Heart & $0.34 \pm 0.21$ & $0.09 \pm 0.04$ \\
Testes & $0.04 \pm 0.04$ & $0.01 \pm 0.01$ \\
Skeletal muscle & $0.06 \pm 0.05$ & $0.00 \pm 0.00$ \\
Brain & $0.05 \pm 0.05$ & $0.04 \pm 0.02$ \\
Skin & $0.04 \pm 0.04$ & $0.03 \pm 0.03$ \\
Plasma & $0.04 \pm 0.04$ & $0.03 \pm 0.03$ \\
RBC & $0.00 \pm 0.00$ &
\end{tabular}

Data are mean \pm SE $n g / g$ cerium concentration, $n=5 /$ group

Ce concentration was estimated $\left(\mathrm{ng} / \mu \mathrm{Ci}_{\mathrm{NPs}} \times \mu \mathrm{Ci} / \mathrm{g}_{\text {tissue }}\right)$

No significant difference was observed between the two group
$\mathrm{CeO}_{2}$ after gavage. Our data showed a rapid clearance of both types of $\mathrm{CeO}_{2}$. We found that nearly $100 \%$ of the uncoated $\mathrm{CeO}_{2}$ and $\sim 95 \%$ of silica-coated $\mathrm{CeO}_{2}$ were eliminated in the feces within 7 days post-gavage. Despite the higher dose we used for gavage, there was negligible radioactivity in any organ or in urine samples collected over a period of 7 days. As has been demonstrated previously, neither $\mathrm{CeO}_{2}$ NP type cross the intestinal barrier nor is there dissolution followed by absorption [15, 32, 61].

\section{Fate of intravenously injected nanoceria}

Due to increasing interest in $\mathrm{CeO}_{2}$ for potential nanomedical applications, we also investigated whether silica coating would affect the tissue distributions of IV-injected $\mathrm{CeO}_{2}$. Consistent with our earlier study [62], both $\mathrm{CeO}_{2}$ types were immediately taken up in organs rich in mononuclear phagocytes with direct access to the circulating blood, such as those in the liver (87 \%), spleen (4\%), and bone $(0.5 \%)$. At $2 \mathrm{~h}$, the total recovered ${ }^{141} \mathrm{Ce}$ in all organs examined were $92.6 \%$ (uncoated) and $92.2 \%$ (silica-coated $\mathrm{CeO}_{2}$ ) of the total injected dose. Despite the significantly higher agglomerate size of uncoated nanoceria after interaction with plasma proteins, their liver uptake measured at $2 \mathrm{~h}$ was not different from silica-coated NPs. However, the silica coating enhanced the overall amount of cerium in some other organs. We found that binding of plasma proteins to the $\mathrm{CeO}_{2}$ surface 


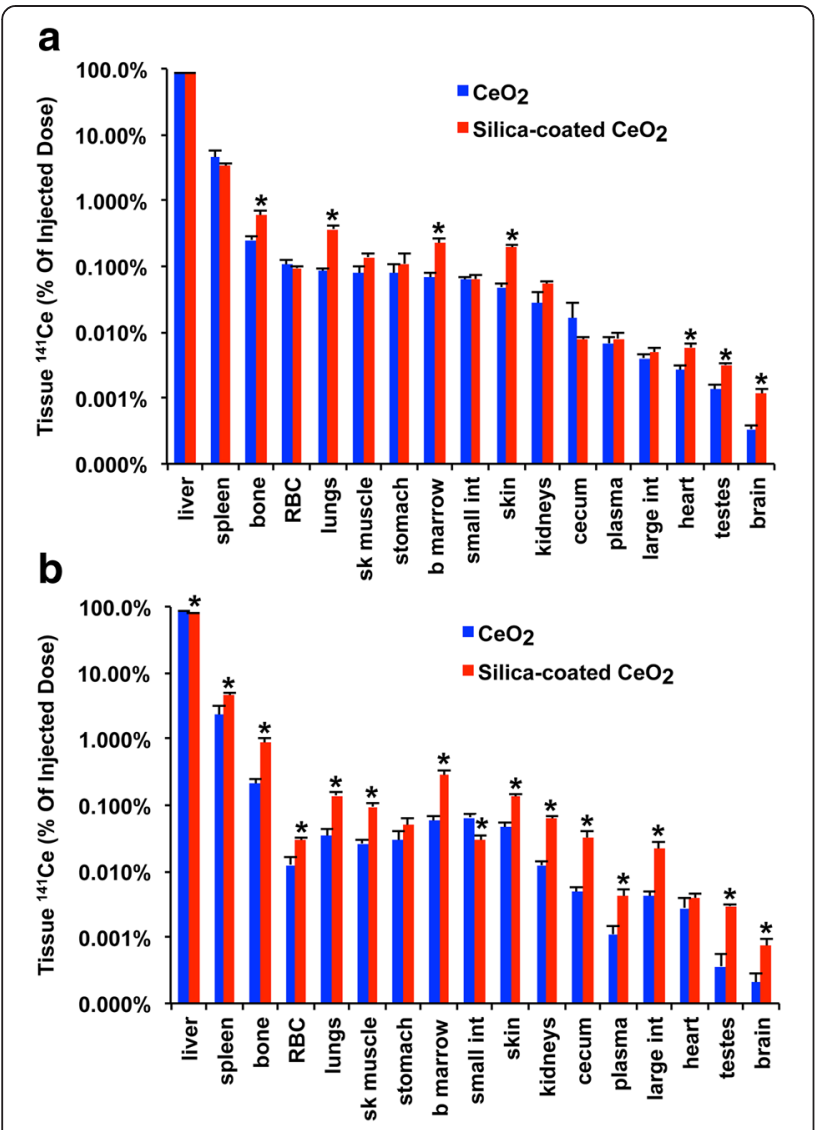

Fig. 8 Tissue distribution of ${ }^{141} \mathrm{Ce}$ post-IV injection of $\mathrm{CeO}_{2} \mathrm{NPs}$. a At $2 \mathrm{~h}$ post-injection, $87 \%$ of ${ }^{141} \mathrm{Ce}$ dose was recovered in the liver, and lower percentages in blood, spleen, bone, and bone marrow from both $\mathrm{CeO}_{2}$ group. b Over a period of 2 days, ${ }^{141} \mathrm{Ce}$ levels in the liver decreased from $87 \%$ to $80 \%$ in the silica-coated group with accompanying increases in the spleen, bone and bone marrow. ${ }^{*} P<0.05$, MANOVA. Data are mean \pm SEM, $n=5 /$ group

was altered by the silica coating. Notably, bound albumin and $\alpha-2$ hs glycoprotein were higher in silica-coated $\mathrm{CeO}_{2}$. A recent study showed that albumin-coated liposomes were taken up more efficiently than uncoated liposomes by murine macrophages [63]. The silica coating in our study also caused a significant reduction (6\%) in the liver retention of ${ }^{141} \mathrm{Ce}$ with concomitant increases in the spleen and bone two days post-exposure. This likely reflects either enhanced dissolution of Kupffer cell-ingested silica-coated $\mathrm{CeO}_{2}$ or the release of intact NPs into the blood likely due to their smaller aggregate size (Table 1 ). Very small amounts of ${ }^{141} \mathrm{Ce}(3.8-5.8 \%)$ were cleared from the body two days post-exposure, indicating that absorbed cerium is biopersistent, as reported in other studies [32, 64].

\section{Conclusions}

In summary, we found that silica coating of $\mathrm{CeO}_{2}$ caused a higher but transient lung inflammation and a higher
Table 4 Cerium concentration in different tissues at 2 hours after intravenous injection of uncoated or silica-coated $\mathrm{CeO}_{2} \mathrm{NPS}$

\begin{tabular}{lcc}
\hline & $\mathrm{CeO}_{2}$ & Silica-coated $\mathrm{CeO}_{2}$ \\
\cline { 2 - 3 } & $\mathrm{ng} / \mathrm{g} \pm \mathrm{SE}$ & $\mathrm{ng} / \mathrm{g} \pm \mathrm{SE}$ \\
\hline Lungs & $14.37 \pm 1.79 \pm 4.93 *$ \\
Liver & $1951.79 \pm 44.49$ & $1663.68 \pm 67.67 *$ \\
Bone & $3.38 \pm 0.44$ & $6.42 \pm 1.14 *$ \\
Cecum & $0.62 \pm 0.43$ & $0.21 \pm 0.03$ \\
Large intestine & $0.36 \pm 0.09$ & $0.28 \pm 0.05$ \\
Bone marrow & $1.73 \pm 0.34$ & $4.67 \pm 0.70 *$ \\
Spleen & $1680.71 \pm 357.91$ & $1204.38 \pm 171.76$ \\
Stomach & $3.77 \pm 1.67$ & $4.77 \pm 2.38$ \\
Kidneys & $3.09 \pm 1.44$ & $5.27 \pm 0.29$ \\
Small intestine & $1.37 \pm 0.20$ & $1.12 \pm 0.14$ \\
Heart & $0.77 \pm 0.15$ & $1.41 \pm 0.26$ \\
Testes & $0.09 \pm 0.02$ & $0.19 \pm 0.01 *$ \\
Skeletal muscle & $0.16 \pm 0.05$ & $0.23 \pm 0.01$ \\
Brain & $0.04 \pm 0.00$ & $0.11 \pm 0.02 *$ \\
Skin & $0.20 \pm 0.03$ & $0.68 \pm 0.04 *$ \\
Plasma & $0.14 \pm 0.03$ & $0.14 \pm 0.03$ \\
RBC & $2.66 \pm 0.51$ & $2.07 \pm 0.23$ \\
\hline Data a mean & &
\end{tabular}

Data are mean $\pm \mathrm{SE} \mathrm{ng} / \mathrm{g}$ cerium concentration, $n=5 /$ group Ce concentration was estimated ( $\left.\mathrm{ng} / \mu \mathrm{Ci}_{\mathrm{NPs}} \times \mu \mathrm{Ci} / \mathrm{g}_{\text {tissue }}\right)$ ${ }^{*} P<0.05, \mathrm{CeO}_{2}$ vs. silica-coated $\mathrm{CeO}_{2}$

lung clearance. It also altered the biodistribution of cerium when $\mathrm{CeO}_{2}$ were injected intravenously. These effects correlated with enhanced adsorption of proteins in lung lining fluid and plasma onto the silica coating. As surface chemistry greatly influences the formation of the nanoparticle corona, our future studies will focus on understanding nano-bio interactions with lung and plasma lipoproteins and their influence on toxicity and biokinetics of NPs.

\section{Methods}

Synthesis of $\mathrm{CeO}_{2}$ and silica-coated $\mathrm{CeO}_{2}$ nanoparticles

Detailed procedures of generating these nanoparticles have been reported $[21,28,33]$. Uncoated and $\mathrm{SiO}_{2}$ coated $\mathrm{CeO}_{2}$ nanoparticles were synthesized by flame spray pyrolysis (FSP) of cerium (III) ethylhexanoate $(0.05 \mathrm{M})$ dissolved in xylene and cerium (III) ethylhexanoate $(0.04 \mathrm{M})$ dissolved in xylene: EHA (3:1), respectively. The precursor solutions were fed through a stainless steel capillary at $5 \mathrm{ml} / \mathrm{min}$, dispersed by $5 \mathrm{~L} / \mathrm{min} \mathrm{O}_{2}$ (Airgas, purity $>99 \%$, pressure drop at nozzle tip: $\rho_{\text {drop }}=2$ bar) and combusted to form the desired nanoparticles. A remixed stoichiometric methane-oxygen $(1.5,3.2 \mathrm{~L} / \mathrm{min})$ supporting flame was used in conjunction with $40 \mathrm{~L} / \mathrm{min}$ $\mathrm{O}_{2}$ sheath gas. In the case of the synthesis of uncoated 
Table 5 Cerium concentration in different tissues at 2 days after intravenous injection of uncoated or silica-coated $\mathrm{CeO}_{2} \mathrm{NPS}$

\begin{tabular}{lcc}
\hline & $\mathrm{CeO}_{2}$ & \multicolumn{1}{c}{ Silica-coated $\mathrm{CeO}_{2}$} \\
\cline { 2 - 3 } & $\mathrm{ng} / \mathrm{g} \pm \mathrm{SE}$ & $\mathrm{ng} / \mathrm{g} \pm \mathrm{SE}$ \\
\hline Lungs & $5.65 \pm 1.53$ & $1652.57 \pm 3.83$ * \\
Liver & $1904.43 \pm 93.22$ & $10.95 \pm 1.617^{*}$ \\
Bone & $2.72 \pm 0.64$ & $0.95 \pm 0.26^{*}$ \\
Cecum & $0.15 \pm 0.02$ & $1.07 \pm 0.29 *$ \\
Large intestine & $0.21 \pm 0.03$ & $6.64 \pm 1.23 *$ \\
Bone marrow & $1.42 \pm 0.28$ & $1822.33 \pm 181.83$ \\
Spleen & $1096.02 \pm 333.49$ & $3.29 \pm 1.25$ \\
Stomach & $2.01 \pm 0.89$ & $6.32 \pm 0.58 *$ \\
Kidneys & $1.32 \pm 0.18$ & $0.63 \pm 0.12 *$ \\
Small intestine & $1.47 \pm 0.14$ & $1.05 \pm 0.12$ \\
Heart & $0.75 \pm 0.26$ & $0.20 \pm 0.02 *$ \\
Testes & $0.02 \pm 0.01$ & $0.18 \pm 0.02 *$ \\
Skeletal muscle & $0.05 \pm 0.01$ & $0.08 \pm 0.02 *$ \\
Brain & $0.02 \pm 0.01$ & $0.52 \pm 0.08 *$ \\
Skin & $0.19 \pm 0.03$ & $0.09 \pm 0.02 *$ \\
Plasma & $0.02 \pm 0.01$ & $0.69 \pm 0.03 *$ \\
RBC & $0.30 \pm 0.69$ &
\end{tabular}

Data are mean $\pm \mathrm{SE} n g / g$ cerium concentration, $n=5 /$ group Ce concentration was estimated ( $\mathrm{ng} / \mu \mathrm{Ci}_{\mathrm{NPs}} \times \mu \mathrm{Ci} / \mathrm{g}_{\text {tissue }}$ ) ${ }^{*} P<0.05, \mathrm{CeO}_{2}$ vs. silica-coated $\mathrm{CeO}_{2}$

$\mathrm{CeO}_{2}, 16 \mathrm{~L} / \mathrm{min}$ of pure $\mathrm{N}_{2}$ was injected into the reactor through a torus ring with 16 equispaced and equisized $\left(\mathrm{d}_{\text {inner }}=0.6 \mathrm{~mm}\right)$ jets at an injection height of $200 \mathrm{~mm}$ above the FSP burner. In the case of $\mathrm{SiO}_{2}$-coated $\mathrm{CeO}_{2}$, $16 \mathrm{~L} / \mathrm{min}_{2}$ carrying hexamethyldisiloxane (HMDSO, Sigma-Aldrich, St. Louis, MO, USA) vapor was fed through the same torus ring at an injection height of $300 \mathrm{~mm}$. HMDSO vapor was obtained by bubbling $0.11 \mathrm{~L} / \mathrm{min}$ gas through liquid HMDSO $(300 \mathrm{ml})$ maintained at $11.3{ }^{\circ} \mathrm{C}$ using a temperature-controlled water bath. At saturation conditions, this corresponds to an HMDSO injection mass of $0.85 \mathrm{~g} / \mathrm{h}$ into the reactor. In both cases, the reactor was enclosed above and below the torus ring by two quartz tubes $\left(\mathrm{d}_{\text {inner }}=45 \mathrm{~mm}\right)$. Uncoated and silica-coated $\mathrm{CeO}_{2}$ NPs were collected on a watercooled glass fiber filter (Whatman) located $80 \mathrm{~cm}$ above the reactor and stored in glass vials prior to experiments.

\section{Neutron activation of $\mathrm{CeO}_{2}$ nanoparticles}

Both nanoparticle powders were neutron activated at the MIT Nuclear Reactor Laboratory (Cambridge, MA) with a thermal neutron flux of $5 \times 10^{13} \mathrm{n} / \mathrm{cm}^{2} / \mathrm{s}$ for $24 \mathrm{~h}$. The process generated the radioisotope ${ }^{141} \mathrm{Ce}$, which decays with a half-life of 32.5 days and emits gamma rays with an energy of $145.4 \mathrm{KeV}$. The specific activity was $2.7 \mu \mathrm{Ci}^{141} \mathrm{Ce}$ per mg $\mathrm{CeO}_{2}$ and $3.4 \mu \mathrm{Ci}{ }^{141} \mathrm{Ce}$ per mg silica-coated $\mathrm{CeO}_{2}$.

\section{Animals}

The protocols used in this study were approved by the Harvard Medical Area Animal Care and Use Committee. Male Wistar Han rats (8 weeks old) were obtained from Charles River Laboratories (Wilmington, MA) and were housed in standard microisolator cages under controlled conditions of temperature, humidity, and light at the Harvard Center for Comparative Medicine. They were fed commercial chow (PicoLab Rodent Diet 5053, Framingham, MA) and were provided with reverse-osmosis purified water ad libitum. The animals were acclimatized in the facility for at least 7 days before the start of experiments.

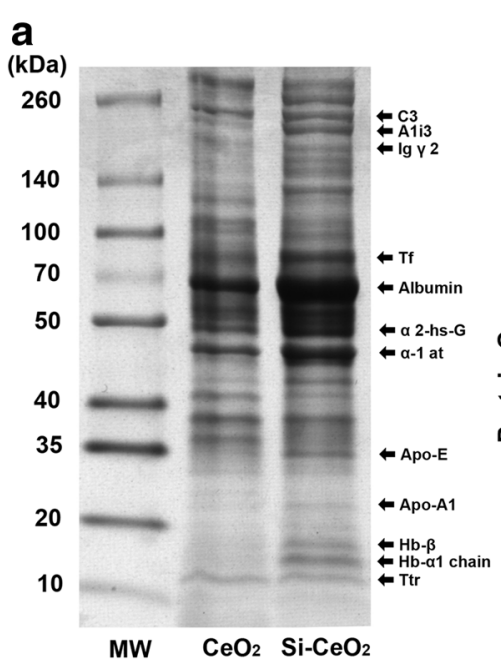

b

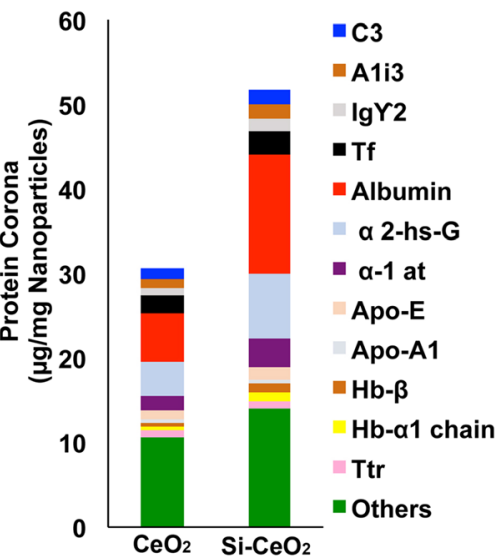

Fig. 9 Analysis of nanoparticle protein corona after incubation in plasma. a Analysis of NP-bound rat plasma proteins by 1D gel electrophoresis. The molecular weights $(\mathrm{kDa})$ of reference proteins are shown in lane MW. Twelve proteins identified by LC-MS are indicated on right. b LC-MS profiles of the same twelve proteins and influence of silica coating on the corona profile 


\section{Preparation of $\mathrm{CeO}_{2}$ nanoparticle suspensions for animal dosing}

Particle suspensions at specified concentrations were prepared in sterile distilled water in conical polyethylene tubes. A critical dispersion sonication energy $\left(\mathrm{DSE}_{\mathrm{cr}}\right)$ to achieve the smallest particle agglomerate size was used, as previously reported [16]. The suspensions were sonicated at $242 \mathrm{~J} / \mathrm{ml}(20 \mathrm{~min} / \mathrm{ml}$ at 0.2 watt power output) in a cup sonicator fitted on Sonifier S-450A (Branson Ultrasonics, Danbury, CT, USA). The sample tubes were immersed in running cold water to minimize heating of the particles during sonication. The hydrodynamic diameter $\left(D_{H}\right)$, polydispersity index (PdI), and zeta potential

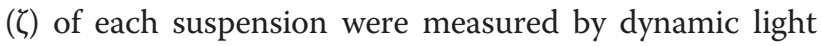
scattering using a Zetasizer Nano-ZS (Malvern Instruments, Worcestershire, UK).

\section{Assessment of pulmonary effects of $\mathrm{CeO}_{2}$ nanoparticles - Bronchoalveolar lavage and analyses}

This experiment was performed to determine the influence of an amorphous silica coating on $\mathrm{CeO}_{2}$ pulmonary effects and also to identify a safe dose for pharmacokinetic studies on instilled materials. Thirty five rats (wt. = $267 \pm 15 \mathrm{~g}$ ) were instilled intratracheally with either uncoated or coated $\mathrm{CeO}_{2} \mathrm{NP}$ suspensions at $0.2,1.0$, and $5 \mathrm{mg} / \mathrm{kg}$ ( $n=5$ rats/ group). Another group of rats were instilled with an equivalent volume of distilled water and served as controls. The particle suspensions were delivered to the lungs through the trachea, as described earlier [35]. Twenty-four hours later, rats were anesthetized and then euthanized via exsanguination, with a cut in the abdominal aorta. The trachea was exposed and cannulated. The lungs were then lavaged 12 times with $3 \mathrm{~mL}$ of $\mathrm{Ca}^{++}$- and $\mathrm{Mg}^{++}$-free $0.9 \%$ sterile PBS. The cells from all washes were separated from the supernatant by centrifugation $\left(350 \times \mathrm{g}\right.$ at $4{ }^{\circ} \mathrm{C}$ for $10 \mathrm{~min})$. Total cell count and hemoglobin measurements were made from the cell pellets. A dilute cell suspension was cytocentrifuged, the cytospin was stained, and differential cell counting was performed. The supernatant from the first two washes was clarified via centrifugation $(14,500 \mathrm{x} \mathrm{g}$ at $4{ }^{\circ} \mathrm{C}$ for $30 \mathrm{~min}$ ), and used for standard spectrophotometric assays for LDH, MPO, and albumin [65].

\section{Pharmacokinetics of intratracheally-instilled, gavaged and intravenously injected ${ }^{141} \mathrm{CeO}_{2}$ nanoparticles}

The nanoparticle dose used for both NPs was $1 \mathrm{mg} / \mathrm{kg}$ for IT instillation, $1 \mathrm{mg} / \mathrm{kg}$ for IV injection, and $5 \mathrm{mg} / \mathrm{kg}$ for gavage administration. Neutron-activated ${ }^{141} \mathrm{CeO}_{2}$ NPs were suspended in sterile distilled water at $0.67 \mathrm{mg} /$ $\mathrm{ml}$ for IT instillation $(1.5 \mathrm{ml} / \mathrm{kg}$ body weight $)$ at $1 \mathrm{mg} / \mathrm{ml}$ for IV injection $(1 \mathrm{ml} / \mathrm{kg})$ or at $5 \mathrm{mg} / \mathrm{ml}$ for gavage administration $(1 \mathrm{ml} / \mathrm{kg})$ and sonicated as described above. The radioactivity in multiple aliquots of each suspension was measured in a WIZARD Gamma Counter (PerkinElmer, Inc., Waltham, MA).

Each rat was anesthetized with isoflurane (Piramal Healthcare, Bethlehem, PA). The ${ }^{141} \mathrm{CeO}_{2}$ NP suspension was delivered to the lungs through the trachea, into the bloodstream via the penile vein, or into the stomach via the esophagus. Each rat was then placed in a metabolic cage with food and water ad libitum for fecal and urine sample collection. Five rats from the IT group were humanely sacrificed at $5 \mathrm{~m}, 2 \mathrm{~d}, 7 \mathrm{~d}$ and $28 \mathrm{~d}$ post-dosing. The same number of rats were analyzed at $5 \mathrm{~m}$ and $7 \mathrm{~d}$ post-gavage, and at $2 \mathrm{~h}$ and $2 \mathrm{~d}$ post-IV injection. Analysis of rats at $5 \mathrm{~min}$ post-IT instillation and post-gavage was performed to obtain an accurate measure of the initial deposited dose. Since we anticipated that clearance from the gastrointestinal tract would be relatively fast, the gavage experiment spanned only 7 days. Twenty four-hour samples of feces and urine were collected at selected time points $(0-24 \mathrm{~h}, 2-3$ days, 6-7 days, 9-10 days, 13-14 days, 20-21 days, and 27-28 days post-IT instillation; 0-24 h, 2-3 days, and 6-7 days post-gavage; and $0-24 \mathrm{~h}$ post-IV injection).

At each endpoint, rats were anesthetized and as much blood as possible was collected from the abdominal aorta. Plasma and red blood cells were separated by centrifugation at $3000 \mathrm{x} \mathrm{g}$ for $10 \mathrm{~min}$ at $4{ }^{\circ} \mathrm{C}$. After euthanasia, the whole lungs, brain, heart, spleen, kidney, gastrointestinal tract, testes, liver, two femoral bones, and multiple samples of skeletal muscle, bone marrow, and skin were collected and placed in pre-weighed tubes. Each sample weight was recorded. Radioactivity was measured in a WIZARD Gamma Counter (PerkinElmer, Inc., Waltham, MA). Disintegrations per minute were calculated from the measured counts per minute (minus background) and the counter efficiency. Data were expressed as $\mu \mathrm{Ci} / \mathrm{g}$ and as a percentage of the administered dose retained in each organ. All radioactivity data were adjusted for physical decay over the entire observation period. The radioactivity in organs and tissues not measured in their entirety was estimated from measured aliquots as a percentage of total body weight as follows: skeletal muscle, $40 \%$; bone marrow, $3.2 \%$; peripheral blood, $7 \%$; skin, $19 \%$; and bone, $6 \%[66,67]$.

\section{Pulmonary distribution of ${ }^{141} \mathrm{CeO}_{2}$ nanoparticles}

To determine the pulmonary distribution of instilled ${ }^{141} \mathrm{CeO}_{2}$ NPs within the lungs at $1 \mathrm{~d}$ post-instillation, a separate cohort of rats were IT-instilled with $1 \mathrm{mg} / \mathrm{kg}$ of either ${ }^{141} \mathrm{CeO}_{2}$ or silica-coated ${ }^{141} \mathrm{CeO}_{2}$. Twenty-four hours later, the lungs were lavaged as described above. The BAL fluid was centrifuged at $350 \mathrm{x}$ g for $10 \mathrm{~min}$ at $4{ }^{\circ} \mathrm{C}$ to separate lavaged cells from the supernatant. The cell pellets were resuspended in $0.5 \mathrm{ml}$ PBS. The 
lavaged lungs, BAL supernatants and cell pellets were analyzed for ${ }^{141} \mathrm{Ce}$. The total radioactivity in each of the three lung compartments was expressed as a percentage of the total radioactivity recovered in the whole lungs.

\section{Characterization of protein corona formation on $\mathrm{CeO}_{2}$ and silica-coated $\mathrm{CeO}_{2}$ nanoparticles in lung lining fluid and plasma}

Nanoparticles $(1 \mathrm{mg} / \mathrm{mL})$ were incubated in $4 \mathrm{~mL}$ rat plasma for $30 \mathrm{~min}$ at $37{ }^{\circ} \mathrm{C}$. Then, the suspension was centrifuged for $10 \mathrm{~min}$ at $14,500 \mathrm{x} \mathrm{g}$. The resulting pellet was washed in DI water three times. After the final washing step, the NP pellet containing 'hard corona' was suspended in $20 \mu \mathrm{L}$ of DI water to which $10 \mu \mathrm{L}$ of $4 \mathrm{x}$ Laemmli sample buffer was added and vortexed. The sample was then heated to $95^{\circ} \mathrm{C}$ for $7 \mathrm{~min}$. After cooling to room temperature, $60 \mu \mathrm{L}$ of mixed solution $(57 \mu \mathrm{L}$ Laemmli and $3 \mu \mathrm{L} \beta \mathrm{ME}$ ) was added to $18 \mu \mathrm{L}$ of the sample. The samples were then loaded onto a gel and proteins were visualized by $1 \mathrm{D}$ SDS-PAGE in combination with Coomassie staining. Gel bands were excised and subjected to a modified in-gel trypsin digestion procedure [68]. Peptides were later extracted and then dried in a speed-vac $(\sim 1 \mathrm{~h})$. The samples were then stored at $4{ }^{\circ} \mathrm{C}$ until analysis. On the day of analysis, the samples were reconstituted in $5-10 \mu \mathrm{L}$ of HPLC solvent A (2.5\% acetonitrile, $0.1 \%$ formic acid). A gradient was formed and peptides were eluted with increasing concentrations of solvent B (97.5\% acetonitrile, $0.1 \%$ formic acid) [69]. Eluted peptides were subjected to electrospray ionization and then analyzed in an LTQ Orbitrap Velos Pro ion-trap mass spectrometer (Thermo Fisher Scientific, San Jose, CA). Peptides were detected, isolated, and fragmented to produce a tandem mass spectrum of specific fragment ions for each peptide. Peptide sequences (and protein identity) were determined by matching protein databases with the acquired fragmentation pattern by the software program, Sequest (ThermoFisher, San Jose, CA).

\section{Assessment of alveolar macrophage uptake of nanoceria in vivo}

Non-radioactive $\mathrm{CeO}_{2}$ and silica-coated $\mathrm{CeO}_{2}$ NPs were instilled in a separate cohort of rats at the same dose and concentration $(1 \mathrm{mg} / \mathrm{kg}, 0.67 \mathrm{mg} / \mathrm{ml})$. At 1 or 5 days post-instillation, rats were sacrificed and their lungs lavaged as described above. BAL cells were cytocentrifuged and fixed on microscope slides. Uptake of nanoceria by cells was analyzed in an Olympus BX-41 microscope (CytoViva ${ }^{\oplus}$, Auburn, AL) hyperspectral image analysis software. Each macrophage was scored for the presence of internalized NPs.

\section{Statistical analyses}

Data were analyzed using multivariate analysis of variance (MANOVA) followed by Bonferroni (Dunn) post hoc tests using SAS Statistical Analysis Software (SAS Institute, Cary, NC). CytoViva data were analyzed by Student $t$ test.

\section{Competing interests}

The authors declare that they have no competing interests.

\section{Authors' contributions}

RMM, NVK, RJ, PD, and JDB designed, performed and evaluated the experimental results. AS performed protein corona evaluation and SF performed CytoViva imaging. This manuscript was written by RMM and NVK and revised by JDB, PD, VC, NVK and RMM. All authors read, corrected, and approved the manuscript.

\section{Acknowledgment}

We kindly acknowledge the financial support from the National Science Foundation (grant no. 1235806), NIH (P30ES000002) and from BASF Ludwigshafen, Germany. This work was performed in part at the Harvard Center for Nanoscale Systems (CNS), a member of the National Nanotechnology Infrastructure Network (NNIN), which is supported by the National Science Foundation under NSF award no. ECS-0335765. The authors also gratefully acknowledge the technical help of Dr. Ross Tomaino with mass spectrometry, Thomas Donaghey for statistical analyses and Melissa Curran for editorial advice.

\section{Author details}

${ }^{1}$ Molecular and Integrative Physiological Sciences Program, Department of Environmental Health, Harvard T.H. Chan School of Public Health, 665 Huntington Avenue, Boston, MA 02115, USA. ${ }^{2}$ National Institute for Occupational Safety and Health, Morgantown, WV, USA. ${ }^{3}$ Department of Basic Pharmaceutical Sciences, School of Pharmacy, West Virginia University, P.O. Box 9530, Morgantown, WV 26506, USA.

Received: 14 July 2015 Accepted: 28 September 2015 Published online: 12 October 2015

\section{References}

1. Bumajdad A, Eastoe J, Mathew A. Cerium oxide nanoparticles prepared in self-assembled systems. Adv Colloid Interface Sci. 2009;147-148:56-66.

2. Heckert EG, Seal S, Self WT. Fenton-like reaction catalyzed by the rare earth inner transition metal cerium. Environ Sci Technol. 2008;42:5014-9.

3. Karakoti AS, Munusamy P, Hostetler K, Kodali V, Kuchibhatla S, Orr G, et al. Preparation and Characterization Challenges to Understanding Environmental and Biological Impacts of Nanoparticles. Surf Interface Anal. 2012;44:882-9.

4. Karakoti AS, Singh S, Kumar A, Malinska M, Kuchibhatla SV, Wozniak K, et al. PEGylated nanoceria as radical scavenger with tunable redox chemistry. J Am Chem Soc. 2009:131:14144-5.

5. Baer DR. Surface Characterization of Nanoparticles: critical needs and significant challenges. J of Surface Anal. 2011;17:163-9.

6. Yokel RA, Hussain S, Garantziotis S, Demokritou P, Castranova V, Cassee FR. The Yin: An adverse health perspective of nanoceria: uptake, distribution, accumulation, and mechanisms of its toxicity. Environ Sci Nano. 2014;1:406-28.

7. Chen J, Patil S, Seal S, McGinnis JF. Rare earth nanoparticles prevent retinal degeneration induced by intracellular peroxides. Nat Nanotechnol. 2006;1:142-50.

8. Horie M, Nishio K, Kato H, Fujita K, Endoh S, Nakamura A, et al. Cellular responses induced by cerium oxide nanoparticles: induction of intracellular calcium level and oxidative stress on culture cells. J Biochem. 2011;150:461-71

9. Ma JY, Mercer RR, Barger M, Schwegler-Berry D, Scabilloni J, Ma JK, et al. Induction of pulmonary fibrosis by cerium oxide nanoparticles. Toxicol Appl Pharmacol. 2012;262:255-64.

10. Srinivas A, Rao PJ, Selvam G, Murthy PB, Reddy PN. Acute inhalation toxicity of cerium oxide nanoparticles in rats. Toxicol Lett. 2011;205:105-15.

11. Colon J, Herrera L, Smith J, Patil S, Komanski C, Kupelian P, et al. Protection from radiation-induced pneumonitis using cerium oxide nanoparticles. Nanomedicine. 2009;5:225-31. 
12. Colon J, Hsieh N, Ferguson A, Kupelian P, Seal S, Jenkins DW, et al. Cerium oxide nanoparticles protect gastrointestinal epithelium from radiation-induced damage by reduction of reactive oxygen species and upregulation of superoxide dismutase 2. Nanomedicine. 2010;6:698-705.

13. Das S, Dowding JM, Klump KE, MCGinnis JF, Self W, Seal S. Cerium oxide nanoparticles: applications and prospects in nanomedicine. Nanomedicine. 2013;8:1483-508

14. Ma JY, Zhao H, Mercer RR, Barger M, Rao M, Meighan T, et al. Cerium oxide nanoparticle-induced pulmonary inflammation and alveolar macrophage functional change in rats. Nanotoxicology. 2011:5:312-25.

15. Molina RM, Konduru NV, Jimenez RJ, Pyrgiotakis G, Demokritou P, Wohlleben W, et al. Bioavailability, distribution and clearance of tracheally instilled, gavaged or injected cerium dioxide nanoparticles and ionic cerium. Environ Sci Nano. 2014;1:561-73.

16. Cohen J, Deloid G, Pyrgiotakis G, Demokritou P. Interactions of engineered nanomaterials in physiological media and implications for in vitro dosimetry. Nanotoxicology. 2013;7:417-31.

17. Pyrgiotakis G, Blattmann CO, Demokritou P. Real-Time Nanoparticle-Cell Interactions in Physiological Media by Atomic Force Microscopy. ACS Sustain Chem Eng. 2014;2:1681-90.

18. Pyrgiotakis G, Blattmann CO, Pratsinis S, Demokritou P. Nanoparticle-nanoparticle interactions in biological media by atomic force microscopy. Langmuir. 2013:29:11385-95.

19. Wohlleben W, Ma-Hock L, Boyko V, Cox G, Egenolf H, Freiberger H, et al. Nanospecific guidance in REACH: A comparative physical-chemical characterization of 15 materials with methodical correlations. J Ceram Sci Tech. 2013:4:93-104

20. Buzea C, Pacheco II, Robbie K. Nanomaterials and nanoparticles: sources and toxicity. Biointerphases. 2007;2:MR17-71.

21. Gass S, Cohen JM, Pyrgiotakis G, Sotiriou GA, Pratsinis SE, Demokritou P. A Safer Formulation Concept for Flame-Generated Engineered Nanomaterials. ACS Sustain Chem Eng. 2013;1:843-57.

22. Konduru NV, Murdaugh KM, Sotiriou GA, Donaghey TC, Demokritou P, Brain $J \mathrm{D}$, et al. Bioavailability, distribution and clearance of tracheally-instilled and gavaged uncoated or silica-coated zinc oxide nanoparticles. Part Fibre Toxicol. 2014:11:44

23. Sotiriou GA, Watson C, Murdaugh KM, Darrah TH, Pyrgiotakis G, Elder A, et al. Engineering safer-by-design, transparent, silica-coated $\mathrm{ZnO}$ nanorods with reduced DNA damage potential. Environ Sci Nano. 2014;1:144-53.

24. Alwi R, Telenkov S, Mandelis A, Leshuk T, Gu F, Oladepo S, et al. Silicacoated super paramagnetic iron oxide nanoparticles (SPION) as biocompatible contrast agent in biomedical photoacoustics. Biomed Opt Express. 2012;3:2500-9.

25. Jana NR, Yu HH, Ali EM, Zheng Y, Ying JY. Controlled photostability of luminescent nanocrystalline $\mathrm{ZnO}$ solution for selective detection of aldehydes. Chem Commun. 2007;1406-1408.

26. Watson C, Ge J, Cohen J, Pyrgiotakis G, Engelward BP, Demokritou P. High-throughput screening platform for engineered nanoparticle-mediated genotoxicity using CometChip technology. ACS Nano. 2014:8:2118-33.

27. Warheit DB, McHugh TA, Hartsky MA. Differential pulmonary responses in rats inhaling crystalline, colloidal or amorphous silica dusts. Scand J Work Environ Health. 1995;21 Suppl 2:19-21.

28. Demokritou P, Gass S, Pyrgiotakis G, Cohen JM, Goldsmith W, McKinney W et al. An in vivo and in vitro toxicological characterisation of realistic nanoscale $\mathrm{CeO}_{2}$ inhalation exposures. Nanotoxicology. 2013;7:1338-50.

29. Lundqvist M, Stigler J, Elia G, Lynch I, Cedervall T, Dawson KA. Nanoparticle size and surface properties determine the protein corona with possible implications for biological impacts. Proc Natl Acad Sci U S A. 2008;105:14265-70.

30. Geraets L, Oomen AG, Schroeter JD, Coleman VA, Cassee FR. Tissue distribution of inhaled micro- and nano-sized cerium oxide particles in rats: results from a 28-day exposure study. Toxicol Sci. 2012;127:463-73.

31. He X, Zhang H, Ma Y, Bai W, Zhang Z, Lu K, et al. Lung deposition and extrapulmonary translocation of nano-ceria after intratracheal instillation. Nanotechnology. 2010;21:285103.

32. Yokel RA, Tseng MT, Dan M, Unrine JM, Graham UM, Wu P, et al Biodistribution and biopersistence of ceria engineered nanomaterials: size dependence. Nanomedicine. 2013;9:398-407.

33. Demokritou P, Buchel R, Molina RM, Deloid GM, Brain JD, Pratsinis SE. Development and characterization of a Versatile Engineered Nanomaterial Generation System (VENGES) suitable for toxicological studies. Inhal Toxicol. 2010;22 Suppl 2:107-16.
34. Ma J, Mercer RR, Barger M, Schwegler-Berry D, Cohen JM, Demokritou P, et al. Effects of amorphous silica coating on cerium oxide nanoparticles induced pulmonary responses. Toxicol Appl Pharmacol. 2015;288:63-73.

35. Brain JD, Knudson DE, Sorokin SP, Davis MA. Pulmonary distribution of particles given by intratracheal instillation or by aerosol inhalation. Environ Res. 1976;11:13-33.

36. Teleki A, Heine MC, Krumeich F, Akhtar MK, Pratsinis SE. In situ coating of flamemade $\mathrm{TiO}_{2}$ particles with nanothin $\mathrm{SiO}_{2}$ films. Langmuir. 2008;24:12553-8.

37. Baisch BL, Corson NM, Wade-Mercer P, Gelein R, Kennell AJ, Oberdorster G, et al. Equivalent titanium dioxide nanoparticle deposition by intratracheal instillation and whole body inhalation: the effect of dose rate on acute respiratory tract inflammation. Part Fibre Toxicol. 2014;11:5.

38. Singh C, Friedrichs S, Ceccone G, Gibson N, Jensen KA, Levin M, et al. Cerium Dioxide, NM-211, NM-212, NM-213. Characterisation and test item preparation., JRC Repository: NM-series of Representative Manufactured Nanomaterials. Ispra, Italy: European Commission Joint Research Centre Institute for Health and Consumer Protection; 2014

39. Bastacky J, Lee CY, Goerke J, Koushafar H, Yager D, Kenaga L, et al. Alveolar lining layer is thin and continuous: low-temperature scanning electron microscopy of rat lung. J Appl Physiol. 1995;79:1615-28.

40. Goerke J. Pulmonary surfactant: functions and molecular composition Biochim Biophys Acta. 1998;1408:79-89.

41. Ruge CA, Schaefer UF, Herrmann J, Kirch J, Canadas O, Echaide M, et al. The interplay of lung surfactant proteins and lipids assimilates the macrophage clearance of nanoparticles. PLoS One. 2012;7:e40775.

42. Schleh C, Hohlfeld JM. Interaction of nanoparticles with the pulmonary surfactant system. Inhal Toxicol. 2009:21 Suppl 1:97-103.

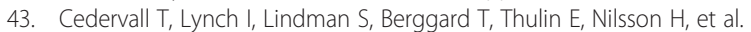
Understanding the nanoparticle-protein corona using methods to quantify exchange rates and affinities of proteins for nanoparticles. Proc Natl Acad Sci U S A. 2007;104:2050-5

44. Milani S, Bombelli FB, Pitek AS, Dawson KA, Radler J. Reversible versus irreversible binding of transferrin to polystyrene nanoparticles: soft and hard corona. ACS Nano. 2012;6:2532-41.

45. Geiser M, Rothen-Rutishauser B, Kapp N, Schurch S, Kreyling W, Schulz H, et al. Ultrafine particles cross cellular membranes by nonphagocytic mechanisms in lungs and in cultured cells. Environ Health Perspect. 2005;113:1555-60.

46. Kim KJ, Malik AB. Protein transport across the lung epithelial barrier. Am J Physiol Lung Cell Mol Physiol. 2003;284:L247-59.

47. Berthiaume $Y$, Albertine KH, Grady M, Fick G, Matthay MA. Protein clearance from the air spaces and lungs of unanesthetized sheep over $144 \mathrm{~h}$. J Appl Physiol. 1989;67:1887-97.

48. Choi HS, Ashitate Y, Lee JH, Kim SH, Matsui A, Insin N, et al. Rapid translocation of nanoparticles from the lung airspaces to the body. Nat Biotechnol. 2010;28:1300-3.

49. Pastva AM, Wright JR, Williams KL. Immunomodulatory roles of surfactant proteins A and D: implications in lung disease. Proc Am Thorac Soc. 2007;4:252-7.

50. Singer L, Colten HR, Wetsel RA. Complement C3 deficiency: human, animal and experimental models. Pathobiology. 1994;62:14-28.

51. Wright JR. Immunoregulatory functions of surfactant proteins. Nat Rev Immunol. 2005:5:58-68.

52. Schulze C, Schaefer UF, Ruge CA, Wohlleben W, Lehr CM. Interaction of metal oxide nanoparticles with lung surfactant protein A. Eur J Pharm Biopharm. 2011;77:376-83.

53. Geiser M, Casaulta M, Kupferschmid B, Schulz H, Semmler-Behnke M, Kreyling $\mathrm{W}$. The role of macrophages in the clearance of inhaled ultrafine titanium dioxide particles. Am J Respir Cell Mol Biol. 2008:38:371-6.

54. Corrin B. Phagocytic potential of pulmonary alveolar epithelium with particular reference to surfactant metabolism. Thorax. 1970;25:110-5

55. Brain JD, Bloom SB, Valberg PA, Gehr P. Correlation between the behavior of magnetic iron oxide particles in the lungs of rabbits and phagocytosis. Exp Lung Res. 1984;6:115-31.

56. Lehnert BE, Morrow PE. Association of ${ }^{59}$ iron oxide with alveolar macrophages during alveolar clearance. Exp Lung Res. 1985:9:1-16.

57. Clemens DL, Lee BY, Xue M, Thomas CR, Meng H, Ferris D, et al. Targeted intracellular delivery of antituberculosis drugs to Mycobacterium tuberculosis-infected macrophages via functionalized mesoporous silica nanoparticles. Antimicrob Agents Chemother. 2012;56:2535-45.

58. Dellinger A, Olson J, Link K, Vance S, Sandros MG, Yang J, et al. Functionalization of gadolinium metallofullerenes for detecting atherosclerotic plaque lesions by cardiovascular magnetic resonance. J Cardiovasc Magn Reson. 2013;15:7. 
59. Konduru NV, Tyurina YY, Feng W, Basova LV, Belikova NA, Bayir $\mathrm{H}$, et al Phosphatidylserine targets single-walled carbon nanotubes to professional phagocytes in vitro and in vivo. PLoS One. 2009;4, e4398.

60. Rollett A, Reiter T, Nogueira P, Cardinale M, Loureiro A, Gomes A, et al. Folic acid-functionalized human serum albumin nanocapsules for targeted drug delivery to chronically activated macrophages. Int J Pharm. 2012;427:460-6.

61. Park E-J, Park Y-K, Park K. Acute toxicity and tissue distribution of cerium oxide nanoparticles by a single oral administration in rats. Toxicol Res. 2009;25:79-84.

62. Brain JD, Molina RM, DeCamp MM, Warner AE. Pulmonary intravascular macrophages: their contribution to the mononuclear phagocyte system in 13 species. Am J Physiol. 1999;276:L146-54.

63. Vuarchey C, Kumar SRS. Albumin coated liposomes: a novel platform for macrophage specific drug delivery. Nanotechnol Dev. 2011;1:5-10

64. Yokel RA, Au TC, MacPhail R, Hardas SS, Butterfield DA, Sultana R, et al. Distribution, elimination, and biopersistence to 90 days of a systemically introduced $30 \mathrm{~nm}$ ceria-engineered nanomaterial in rats. Toxicol Sci. 2012;127:256-68

65. Beck BD, Brain JD, Bohannon DE. An in vivo hamster bioassay to assess the toxicity of particulates for the lungs. Toxicol Appl Pharmacol. 1982;66:9-29.

66. Brown RP, Delp MD, Lindstedt SL, Rhomberg LR, Beliles RP. Physiological parameter values for physiologically based pharmacokinetic models. Toxicol Ind Health. 1997;13:407-84

67. Schoeffner DJ, Warren DA, Muralidara S, Bruckner JV, Simmons JE. Organ weights and fat volume in rats as a function of strain and age. J Toxicol Environ Health A. 1999:56:449-62.

68. Shevchenko A, Wilm M, Vorm O, Mann M. Mass spectrometric sequencing of proteins silver-stained polyacrylamide gels. Anal Chem. 1996:68:850-8.

69. Peng J, Gygi SP. Proteomics: the move to mixtures. J Mass Spectrom. 2001:36:1083-91.

\section{Submit your next manuscript to BioMed Central and take full advantage of:}

- Convenient online submission

- Thorough peer review

- No space constraints or color figure charges

- Immediate publication on acceptance

- Inclusion in PubMed, CAS, Scopus and Google Scholar

- Research which is freely available for redistribution 